Journal of Natural Products

April 2018, Volume 81, Issue 4, Pages 885-893

http://dx.doi.org/10.1021/acs.jnatprod.7b00973

http://archimer.ifremer.fr/doc/00428/54001/

(C) 2018 The American Chemical Society and American Society of

Pharmacognosy

\title{
Identification of 21,22-Dehydroazaspiracids in Mussels (Mytilus edulis) and in Vitro Toxicity of Azaspiracid-26
}

\author{
Kilcoyne Jane ${ }^{1,{ }^{*}}$, Mccarron Pearse ${ }^{2}$, Twiner Michael J. ${ }^{3}$, Rise Frode ${ }^{4}$, Hess Philipp ${ }^{5}$, \\ Wilkins Alistair L. ${ }^{6}$, Miles Christopher O. ${ }^{2,6}$
}

\footnotetext{
${ }^{1}$ Marine Institute, Rinville, Oranmore, Co. Galway H91 R673, Ireland

${ }^{2}$ Measurement Science and Standards, National Research Council Canada, Halifax, NS B3H3Z1, Canada

${ }^{3}$ Department of Emergency Medicine,Detroit Receiving Hospital, Wayne State University, Detroit, Michigan 48202, United States

${ }_{5}^{4}$ Department of Chemistry, University of Oslo, N-0315 Oslo, Norway

${ }^{5}$ Ifremer, Laboratoire Phycotoxines, Rue del'lle d'Yeu, 44311 Nantes, France

${ }^{6}$ Norwegian Veterinary Institute, P.O. Box 750 Sentrum, 0106 Oslo, Norway

* Corresponding author : Jane Kilcoyne, email address : jane.kilcoyne@marine.ie
}

\begin{abstract}
:
Azaspiracids (AZAs) are marine biotoxins produced by the genera Azadinium and Amphidoma, pelagic marine dinoflagellates that may accumulate in shellfish resulting in human illness following consumption. The complexity of these toxins has been well documented, with more than 40 structural variants reported that are produced by dinoflagellates, result from metabolism in shellfish, or are extraction artifacts. Approximately $34 \mu \mathrm{g}$ of a new AZA with MW 823 Da (AZA26 (3)) was isolated from blue mussels (Mytilus edulis), and its structure determined by MS and NMR spectroscopy. AZA26, possibly a bioconversion product of AZA5, lacked the C-20-C-21 diol present in all AZAs reported thus far and had a 21,22-olefin and a keto group at C-23. Toxicological assessment of 3 using an in vitro model system based on Jurkat $T$ lymphocyte cells showed the potency to be $\sim 30$-fold lower than that of AZA1. The corresponding 21,22-dehydro-23-oxo-analogue of AZA10 (AZA28) and 21,22-dehydro analogues of AZA3, -4, -5, -6, -9, and -10 (AZA25, -48 (4), -60, -27, -49, and -61, respectively) were also identified by HRMS/MS, periodate cleavage reactivity, conversion from known analogues, and NMR (for 4 that was present in a partially purified sample of AZA7).
\end{abstract}


Since the first identification and characterization of azaspiracid (AZA1) (1) in 1998, ${ }^{1}$ more than 40 additional analogues have been reported (Figure 1). ${ }^{2-9}$ Following the isolation of 1, AZA2 (2) and AZA3-5 were purified from shellfish and their structures elucidated. ${ }^{2,3}$ Only 1, 2 and AZA3 are regulated $\left(160 \mu \mathrm{g} / \mathrm{kg}\right.$ AZA1 equivalents in raw whole flesh). ${ }^{10}$ Certain Azadinium spp. produce $\mathbf{1}$ and $\mathbf{2}^{11}$ while many of the other AZAs are shellfish metabolites. ${ }^{12,13}$ A metabolic pathway for some of the analogues has been proposed. ${ }^{14}$ Studies on the effects of heating blue mussels (Mytilus edulis) contaminated with AZAs revealed that levels of AZA3, -4, -5, -6, -9,$10,-13$ and -15 increased when samples were heat treated due to thermal decarboxylation of their corresponding 22-carboxyAZAs (AZA17, -21, -44, -19, -23, -45, -46 and -47, respectively). ${ }^{14,15}$

An improved isolation procedure was reported for the purification of $\mathbf{1 , 2}$, and AZA3 and led to isolation and characterisation of AZA6. ${ }^{16}$ More recently, the isolation, structures and toxicities of 37-epi-1, ${ }^{17}$ AZA33 and $-34^{18}$ and AZA7-10 $0^{19}$ have been described. Of the analogues that have been characterised to date, structural variations have been observed (Figure 1) resulting in varying potencies. In vitro (using the Jurkat T lymphocyte cell assay), the order of potency is: $\mathbf{2}$ $>\mathrm{AZA} 6>\mathrm{AZA} 34 \approx 37-$ epi-1 > $\mathrm{AZA} 8 \approx \mathrm{AZA} 3>\mathbf{1}>\mathrm{AZA} 4 \approx \mathrm{AZA} 9>\mathrm{AZA} 5 \approx \mathrm{AZA} 10>$ AZA33. ${ }^{5}$ The results suggest that AZA potency is increased by methylation at C-8 and/or C-22 (2, AZA6) and reduced by hydroxylation at C-3 and/or C-23 (AZA4, -5). AZA8, which has a methyl group at C-22 and a hydroxy group at C-3, was found to be more toxic than $\mathbf{1}$, while AZA9 and -10 , both of which are methylated at C-8 and hydroxylated at C-3 and C-23, respectively, were less potent. ${ }^{19}$ AZA33 (1 missing the A/B/C rings) was less potent than 1 ( $\sim$ fold), whereas AZA34 (1 missing the C-4/C-5 alkene) was 5.5-fold more potent than 1 . Similarly, 37-epi-1 was 5.1-fold more potent than 1. AZAs induce cell lysis via apoptotic pathways ${ }^{20}$ and are $\mathrm{K}^{+}$channel blockers, ${ }^{21}$ however the mode of action that induces cytotoxicity has not yet been established. ${ }^{22}$

Rehmann et al. reported the tentative identification of AZA25 (21,22-dehydroAZA3) in extracts from M. edulis, and postulated the existence of AZA26-28 (21,22-dehydroAZA1, 21,22dehydroAZA6, and 21,22-dehydroAZA2, respectively). ${ }^{4}$ In this paper we report the isolation of a compound corresponding to the $m / z$ of AZA26 at unit-resolution, and its identification by LCMS and NMR spectroscopy as 21,22-dehydro-23-oxoAZA3 (3) (Figure 1). We also report the tentative identification of 21,22-dehydro-23-oxoAZA6 (AZA28) and the identification of AZA25, -48, -60, -27, -49, and -61 as 21,22-dehydro analogues of AZA3, -4, -5, -6, -9 and -10 
respectively using LC-MS, periodate reactivity, and chemical interconversions, as well as NMR spectroscopy in the case of AZA48 (4). Compound 3 was tested for in vitro toxicity, and found to be $\sim 30$-fold less toxic than $\mathbf{1}$.

\section{RESULTS AND DISCUSSION}

Compound 3 (34 $\mu \mathrm{g}$ ) was isolated from mussel (M. edulis) hepatopancreas using the method previously described for AZA6. ${ }^{16}$ The final step in the procedure, which employed chromatography with a neutral mobile phase due to instability in acidic mobile phases ${ }^{23}$ resulted in the separation of $\mathbf{3}$ from AZA4. Due to the very low levels of $\mathbf{3}$ present in the sample and coelution of other compounds, two additional semi-preparative HPLC steps were required to achieve sufficient purity for NMR analysis and toxicity testing. The additional purification steps led to significant losses and therefore reduced recoveries. The stability of $\mathbf{3}$ was assessed over a period of 7 days at $-18{ }^{\circ} \mathrm{C},+20{ }^{\circ} \mathrm{C}$ and $+40{ }^{\circ} \mathrm{C}$ in $\mathrm{MeOH}$. Compound 3 exhibited good stability at $-18{ }^{\circ} \mathrm{C}$ and at $+20{ }^{\circ} \mathrm{C}$ over 7 days, however at $+40{ }^{\circ} \mathrm{C}$, some degradation $(\sim 17 \%)$ was observed (Figure S4).

A compound named AZA26 with $\mathrm{m} / \mathrm{z} 824.5$ was first postulated by analogy with the tentatively identified AZA25 by Rehmann et al. ${ }^{4}$ It was proposed that AZA26 would be formed by loss of $\mathrm{H}_{2} \mathrm{O}$ from 1 to form a double bond between C-21 and C-22. The authors also proposed that the equivalent 21,22-dehydro congeners existed for AZA3 (AZA25), 2 (AZA28) and AZA6 (AZA27). ${ }^{4}$ AZA25 was observed by Rehmann et al., but no evidence for the existence of AZA26-28 was found, either in crude mussel extracts or as isolation artefacts during the purification of AZAs. ${ }^{4}$

Structure Elucidation. The MS/MS spectrum of 3 (Figure S3E) showed typical AZA-type fragmentations including $\mathrm{H}_{2} \mathrm{O}$ loss $(\mathrm{m} / \mathrm{z}, 806)$ and retro-Diels-Alder cleavage $(\mathrm{m} / \mathrm{z}, 672)$ fragments as well as fragments at $\mathrm{m} / \mathrm{z} 362$ and 462 (although the latter was much weaker than in 1) that indicated that the amine end of $\mathbf{1}$ was present. The greatly reduced intensity of the fragment at $\mathrm{m} / \mathrm{z} 462$ suggested a structural modification close to C-20. Analysis by LC-HRMS (Table 2) indicated 3 to have $m / z, 824.4576$, consistent with $\mathrm{C}_{46} \mathrm{H}_{66} \mathrm{NO}_{12}{ }^{+}$and not consistent with the composition of the hypothetical AZA26 $\left(\mathrm{C}_{47} \mathrm{H}_{70} \mathrm{NO}_{11}{ }^{+}\right.$, expected $m / z$ 824.4943) of Rehmann et al. ${ }^{4}$ Furthermore, while the fragment at $\mathrm{m} / \mathrm{z} 362.2680$ corresponded to the expected composition $\left(\mathrm{C}_{22} \mathrm{H}_{36} \mathrm{NO}_{3}{ }^{+}, \Delta-2.7 \mathrm{ppm}\right)$, the fragment at $\mathrm{m} / \mathrm{z} 462.2845$ corresponded to $\mathrm{C}_{26} \mathrm{H}_{40} \mathrm{NO}_{6}{ }^{+}(\Delta-1.1 \mathrm{ppm})$ rather than to $\mathrm{C}_{27} \mathrm{H}_{44} \mathrm{NO}_{5}{ }^{+}(\mathrm{m} / z$ 462.3214) that would be expected for 
21,22-dehydroAZA1, consistent with the loss of the 22-methyl group and the insertion of a carbonyl group in the E-ring of $\mathbf{1}$.

Examination of the one and two-dimensional NMR spectra of 3 demonstrated the presence of intact AZA-type C-1-C-20 and C-26-C-40 structural sub-units, with chemical shifts and coupling constants similar to those obtained for $\mathbf{1}$ under similar conditions (Table 1). The coupling constants for H-17-H-20 of 3 (Figure S23) were very similar to those observed for natural AZA3 and synthetic (20S)-AZA $3,{ }^{24}$ indicating that $\mathbf{3}$ shares the $20 S$-configuration present in AZA1-10 and -34. However, the NMR spectra revealed the presence of an $\alpha, \beta$-unsaturated keto group in ring-E which exhibited ${ }^{13} \mathrm{C}$ signals at 176.7, 103.5 and $198.1 \mathrm{ppm}$. Correlations observed in the HSQC spectrum of $\mathbf{3}$ showed that a proton (5.49 ppm, H-22) was attached to the carbon resonating at $103.5 \mathrm{ppm}$, but not to the carbon signal at $176.7 \mathrm{ppm}$. The 24-methyl protons (1.06 ppm) exhibited an HMBC correlation to the carbonyl signal at $198.1 \mathrm{ppm}$, as did H-24 (2.57 ppm) and H-25 (4.61 ppm). These and other HMBC correlations (Figure 3) unambiguously established the structure of $\mathbf{3}$. The chemical shifts for C-21-C-23 and H-22 of $\mathbf{3}$ are similar to those for the corresponding atoms in 2-methyl-5,6-dihydro-4-pyrone. ${ }^{25}$

LC-PDA (photodiode array) analysis showed that 3 exhibited a $\lambda_{\max }$ of $266 \mathrm{~nm}$ (Figure S2), slightly higher than a standard $\alpha, \beta$-unsaturated keto group $(\sim 215-250 \mathrm{~nm})$. The longer wavelength is consistent with an oxygen in the beta position. This chromophore is not present in the other AZA analogues isolated to date (Figure 1). Compound 3 was unreactive with periodate, which cleaves the diol moiety of AZAs at C-20,21 to produce a lactone, and did not produce the structurally diagnostic C-20,21-diol-cleavage product $(\mathrm{m} / \mathrm{z}, 448)$ that is obtained by periodate treatment of $\mathbf{1},{ }^{19}$ suggesting the absence of a C-20,21-diol sub-unit in $\mathbf{3}$. These findings are fully consistent with the proposed structure of $\mathbf{3}$. The structure of $\mathbf{3}$ suggests that it may be a bioconversion product of 1 produced via dehydration and oxidation (C-23 hydroxy to C-23 keto) of AZA5, and therefore should have the same absolute configuration as $\mathbf{1}$.

The finding of $\mathbf{3}$, and its identification as 21,22-dehydro-23-oxoAZA3, prompted a more detailed examination of the M. edulis extract for other 21,22-dehydroAZAs by LC-MS before and after treatment with periodate, (to confirm whether the C-20,21-diol was present or absent (Figure S1)). In addition to $\mathbf{3}$, a range of other putative 21,22-dehydroAZAs were detected (Figure 1, Figure 2, Table 2), including the previously reported ${ }^{4}$ AZA25 and the postulated ${ }^{4}$ analogue AZA27. However, as was the case with AZA26 (3), there was no sign of AZA28 (21,22dehydroAZA2, $\mathrm{C}_{48} \mathrm{H}_{72} \mathrm{NO}_{11}{ }^{+}$calcd $m / z$ 838.5100) as originally proposed by Rehmann et al., ${ }^{4}$ and 
the only 21,22-dehydroAZA detected with $\mathrm{m} / \mathrm{z} 838.5$ was found by LC-HRMS to have $[\mathrm{M}+\mathrm{H}]^{+}$ at $m / z$ 838.4742. This value of $m / z$ is consistent with $\mathrm{C}_{47} \mathrm{H}_{68} \mathrm{NO}_{12}{ }^{+}(\Delta 0.7 \mathrm{ppm})$, and not with the composition originally proposed by Rehmann et al. for AZA28. ${ }^{4}$ This compound eluted $\sim 0.2 \mathrm{~min}$ earlier than AZA10, similar to the difference in elution time between $\mathbf{3}$ and AZA5, and its MS/MS spectrum (Figure S3N) showed AZA-type fragmentations essentially identical to those of 3, including $\mathrm{H}_{2} \mathrm{O}$ loss $(\mathrm{m} / \mathrm{z}$ 806) and retro-Diels-Alder cleavage $(\mathrm{m} / \mathrm{z}, 672)$ fragments as well as fragments at $\mathrm{m} / \mathrm{z}, 362$ and 462 (the latter very weak, as in 3) that indicated that the C-24-C40 moiety of 1 was present but that, relative to 3 , an additional $\mathrm{CH}_{2}$ unit was present between $\mathrm{C}-1$ and C-9 (presumably due to a methyl group at C-8, as in AZA2). Therefore, the name AZA28 is reassigned to the compound detected in the present study, which is tentatively identified as 21,22-dehydro-23-oxoAZA6 (Figure 1).

LC-MS evidence for the existence of AZA60 and -61 was obtained, showing expected masses (Table 2) and fragmentation patterns (Figure S3D and S3M). Both analogues showed fragments at $m / z 464$ (Figures S3D and S3M), as was the case for AZA5 and -10 (Figures S3C and S3L). The equivalent fragments for 3 and AZA28 had $\mathrm{m} / \mathrm{z}$ of 462 which is consistent with an oxidation at C-23. AZA60 and -61 co-eluted with 3 and AZA28 respectively using LC-MS method A(i), however, they were resolved (Figures S5 and S6) using LC-MS method A(ii).

The formation of $\mathbf{3}$ is proposed to occur via 22-decarboxylation of AZA44 ${ }^{14}$ to form AZA5 followed by 21,22-dehydration (to form AZA60) and C-23 oxidation (Figures 4 and S47). No evidence for the equivalent AZA8 (also C-23 hydroxylated) dehydration product could be found. The formation of AZA28 is proposed to occur in a similar manner to $\mathbf{3}$, via AZA45, ${ }^{14}$ AZA10 and AZA61 (Figures 4 and S47).

As in the study of Rehmann et al., ${ }^{4}$ AZA25 (21,22-dehydroAZA3) was detected in the M. edulis extracts (Figures 2 and S3B). The mass spectrum of AZA25 showed that the $\mathrm{H}_{2} \mathrm{O}$ loss fragments were less prominent, however, and, like 3 (and AZA28), the $m / z 362$ fragment was dominant. Further evidence for the existence of 21,22-dehydroAZA4 (AZA48 (4)), -6 (AZA27) and -9 (AZA49) (Table 2, Figures 2, S3I, S3K and S3G) was found, however levels of the other analogues (21,22-dehydro AZA13 and -15) were too low to detect. Treatment of a cooked hepatopancreas extract with periodate, resulted in the disappearance of all of the 20,21dihydroxyAZAs but no changes were observed for the dehydrated analogues (AZA25, -27, 4, 49, -60 and -61) nor for 3 and AZA28 (Figure 2, S5 and S6). This provided further evidence that these analogues lack a 20,21 diol. 
A short-term study was performed to test whether the dehydration of $\mathbf{1}$ and AZA3 can occur spontaneously, or whether it requires enzymatic catalysis during metabolism in the shellfish. AZA25 was rapidly formed as a minor product when a mixture of $\mathbf{1}$ and AZA3 were stored in $\mathrm{MeOH}$ at $60{ }^{\circ} \mathrm{C}$ (Figures S24 and S25), whereas only traces of the dehydration product from 1 were detectable by LC-MS even after 14 days. Addition of a small amount of formic acid significantly increased the abundance of AZA25, suggesting that the dehydration reaction is acid catalysed. Thus, AZA3 is much more prone to dehydration than its 22-methylated congener 1, and although this stability study was conducted at an elevated temperature, the same reactions can be expected to occur, albeit more slowly, at ambient temperatures. Thus, a small proportion of the 22-demethylated AZAs in shellfish and their extracts will spontaneously undergo 21,22dehydration, while the same reaction for 22-methylAZAs will usually be too slow to be detectable even in heated samples. This accounts for our inability to detect any 21,22dehydroAZAs that contained a methyl group at C-22 in natural samples.

The available evidence is consistent with the pathway shown in Figures 4 and S47. In a previous study the purity of AZA7 was compromised by the presence of a co-eluting compound with $\mathrm{m} / \mathrm{z}$ 826 together with AZA5. ${ }^{19}$ We suspected the compound with $\mathrm{m} / \mathrm{z} 826$ to be AZA48 (4), and reinvestigated the NMR data from the sample of AZA7 that included this compound in more detail. By LC-HRMS and NMR the sample was shown to consist $\sim 65 \%$ AZA7, $20 \%$ of a compound with $\mathrm{m} / \mathrm{z}, 826.4732$ compound $\left(\mathrm{C}_{46} \mathrm{H}_{68} \mathrm{NO}_{12}{ }^{+}, \Delta-0.4\right.$ ppm; putative 4), and $14 \%$ AZA5. In the ${ }^{1} \mathrm{H}$ NMR spectrum the $20 \%$-contaminant had a resonance at $4.75 \mathrm{ppm}(\mathrm{H}-22, \mathrm{dd}, J$ $=2.3,4.8 \mathrm{~Hz})$ that exhibited COSY correlations to protons at 1.80 and $2.08 \mathrm{ppm}\left(\mathrm{H}-23_{\mathrm{ax}}\right.$ and $\mathrm{H}-$ $\left.23_{\mathrm{eq}}\right)$ and an HSQC correlation to a signal at $99.5 \mathrm{ppm}$ (C-22), while a signal at $3.87 \mathrm{ppm}(\mathrm{H}-25$, $\mathrm{d}, J=9.0 \mathrm{~Hz})$ showed a COSY correlation to a proton at $1.67 \mathrm{ppm}(\mathrm{H}-24)$ and an HSQC correlation to a carbon at $84.8 \mathrm{ppm}(\mathrm{C}-25)$. In the TOCSY NMR spectra, the signals at 4.75 and $3.87 \mathrm{ppm}$ both correlated to each other as well as to protons resonating at 0.93 (24-Me, d, $\mathrm{J} \approx 7$ $\mathrm{Hz}), 1.67$ (H-24), 1.80 and $2.08 \mathrm{ppm}\left(\mathrm{H}-23_{\mathrm{ax}}\right.$ and $\left.\mathrm{H}-23_{\mathrm{eq}}\right)$. The signal at $4.75 \mathrm{ppm}(\mathrm{H}-22)$ showed ROESY NMR correlations to the H-23 methylene protons and to a signal at $3.75 \mathrm{ppm}(\mathrm{H}-20)$, that in turn correlated in COSY, TOCSY, and HSQC NMR spectra with signals that allowed identification of resonances associated with C-16-C-20 of AZA48 (4). Similarly, the signal at 3.87 ppm (H-25) showed ROESY NMR correlations to signals at 1.80 (H-23 $)$ ), 5.29 (26-olefinic methylene), and $2.22(\mathrm{H}-27, \mathrm{~d} J=13.6 \mathrm{~Hz})$. Correlations from the two latter signals in the COSY, TOCSY, ROESY, HSQC and HMBC spectra allowed assignment of the resonances associated with C-26-C-28 of 4. Unsurprisingly, the remaining resonances for 4 were not 
distinguishable from those of the AZA7 present in the sample because these two compounds differ only at C-21 and C-22. The chemical shift of C-22 of 4 (99.5 ppm) is similar to that of C-5 of 2,3-dihydropyran in $\mathrm{CDCl}_{3}(100.6 \mathrm{ppm}),{ }^{25}$ and the NMR assignments (Table 1, Figure S26) together with the evidence from LC-MS analysis establish 4 as 21,22-dehydroAZA4. Heating solutions of pure AZA4 in $\mathrm{MeOH}$ or formic acid in $\mathrm{MeOH}$ resulted in partial conversion to a compound of $\mathrm{m} / \mathrm{z} 826.4727$ with the same retention time as the 4 in the M. edulis extract and in the partially purified sample of AZA7, thereby confirming its identity and suggesting spontaneous dehydration as a plausible origin for this and other 21,22-dehydroAZAs (Figures S40-42). Heating solutions of purified samples of AZA5, -6, -9 and -10 in acidic $\mathrm{MeOH}$ also showed partial conversion to AZA60, -27, -49 and -61 respectively (Figures S43-46), thereby additionally confirming their identities.

LC-FLD Analysis of ADAM Derivatives. An insufficient quantity of purified 3 was isolated to enable quantitative NMR. Analysis of the sample by LC-MS in SIM mode and under isocratic conditions (to limit any differences in relative responses) against a certified reference material (CRM) of 1 gave an indicative concentration. However, to accurately determine the relative toxicity of 3 , the 9-anthryldiazomethane (ADAM)-FLD method ${ }^{27}$ was used to assign a concentration $(1.18 \mu \mathrm{g} / \mathrm{mL})$, by calibrating against a CRM of $2 .{ }^{28}$ Including isomeric impurities, the total concentration was $1.45 \mu \mathrm{g} / \mathrm{mL}$ (Figure S7).

Toxicity. As with other AZAs tested in previous studies, 3 caused a cytotoxic response in a timeand concentration-dependent manner, with $\mathrm{EC}_{50}$ values of $24 \mathrm{nM}, 39 \mathrm{nM}$, and $30 \mathrm{nM}$ for 24, 48, and $72 \mathrm{~h}$ of continuous exposure, respectively (Table 3, Figure S48). Compared to 1, compound 3 was $\sim 30$-fold less potent, making it by far the least potent of all AZA analogues tested to date. , $^{6}$ ${ }^{17-19,29}$ This compound differs from all other AZA analogues reported thus far, by having an $\alpha, \beta-$ unsaturated keto group spanning C-21 to C-23 and lacking the C-20,21-diol group. These results suggest that this middle part of the molecule is important for biological activity. This is consistent with the study by Ito et $\mathrm{al}^{30}$ in which inverting the configuration of the entire left-hand side (C-1-C-20) of a synthetic AZA1 analogue was found to decrease the toxicity to only 25\% that of 1 in mice. Similarly, AZA33 shares only C-18-C-40 with 1, but nonetheless retained $\sim 20 \%$ of the toxicity of $\mathbf{1}$ in the Jurkat $\mathrm{T}$ cell bioassay. ${ }^{18}$ Thus, it appears that the C-21-C40 moiety of the AZAs is primarily responsible for their toxicity. It is unknown at this point whether the dehydrated AZAs that do not have the keto functionality at C-23 (21,22-dehydro AZA3, -4, 6, and -9) exhibit similar potencies to $\mathbf{3}$, or whether the reduced potency of $\mathbf{3}$ is due to the 
absence of the C-20,21-diol group.

\section{CONCLUSION}

AZA26 (3) was isolated from blue mussels and its structure was determined by LC-MS and oneand two-dimensional NMR. Compound 3 possesses an $\alpha, \beta$-unsaturated-keto group and lacks the 20,21-diol that is typically present in AZAs. Cytotoxicity was assessed employing Jurkat T lymphocyte cells and the potency of $\mathbf{3}$ relative to $\mathbf{1}$ was found to be 0.03 ( 230 times less). Compound 3 is proposed to result from a 21,22 dehydration together with C-23 oxidation of AZA5, produced by decarboxylation of AZA44. Dehydrated analogues of AZA3, -4, -6, -9 and 10 were identified by HRMS/MS (for AZA3, -4 and -6) in M. edulis extracts. Their formation was additionally observed in heated/acidic solutions of the purified analogues. AZA48 (4) was identified by LC-MS as a $\sim 20 \%$ component of a partially purified sample of AZA7, and its structure was further verified by NMR analysis and by HRMS/MS comparison with $\mathbf{4}$ produced by heat/acid-promoted dehydration of AZA4. These dehydrated AZAs were present in shellfish at very low levels and are not considered of relevance to human health. Nevertheless, the marked reduction in toxicity observed for $\mathbf{3}$ extends knowledge concerning the chemical stability of AZAs and their structure-activity relationships.

\section{EXPERIMENTAL SECTION}

\section{General Experimental Procedures}

Purification of 3 was achieved by semi-preparative LC (Agilent 1200) with PDA detection (210 $\mathrm{nm}$ ) using a Cosmosil C18 column, $5 \mu \mathrm{m}, 250 \times 4.6 \mathrm{~mm}$ (Nacalai tesque) eluted with $\mathrm{CH}_{3} \mathrm{CN} / \mathrm{H}_{2} \mathrm{O}(1: 1$, plus $2 \mathrm{mM}$ ammonium acetate) at $1 \mathrm{~mL} / \mathrm{min}$. The column temperature was 30 ${ }^{\circ} \mathrm{C}$. Purity was determined using a semi-preparative system (Shimadzu 10AVp) with PDA detection using the same LC conditions.

NMR experiments for structure elucidation were run using Bruker Avance I and Avance II 600 $\mathrm{MHz}$ spectrometers equipped with TCI cryoprobes and Z-gradient coils, at $30^{\circ} \mathrm{C}$.

Structure determination and accurate mass measurements were performed using two methods. Method A used a Waters Acquity UPLC coupled to a Xevo G2-S QToF monitoring in MS ${ }^{\mathrm{e}}$ and MS/MS modes (AZA3, $m / z$ 828.5; AZA25, $m / z$ 810.5; AZA4 and AZA5, $m / z$ 844.5; AZA48 and AZA60, 826.5; AZA6, 842.5; AZA26 and AZA27, 824.5; AZA9 and AZA10, 858.5; AZA49 and AZA61, 840.5; AZA28, 838.5) using leucine enkephalin as the reference compound. The 
cone voltage was $40 \mathrm{~V}$, collision energy was $50 \mathrm{~V}$, the cone and desolvation gas flows were set at 0 and $600 \mathrm{~L} / \mathrm{h}$, respectively, and the source temperature was $120{ }^{\circ} \mathrm{C}$.

(i) Chromatography was performed with an Acquity UPLC CSH C18 $(50 \times 2.1 \mathrm{~mm}, 1.7 \mu \mathrm{m})$ column (Waters). Binary gradient elution was used, with phase A consisting of $\mathrm{H}_{2} \mathrm{O}$ and phase $\mathrm{B}$ of $\mathrm{CH}_{3} \mathrm{CN}$ (95\%) in $\mathrm{H}_{2} \mathrm{O}$ (both containing $2 \mathrm{mM}$ ammonium formate and $50 \mathrm{mM}$ formic acid). The gradient was from $30-90 \% \mathrm{~B}$ over $5 \mathrm{~min}$ at $0.3 \mathrm{~mL} / \mathrm{min}$, held for $0.5 \mathrm{~min}$, and returned to the initial conditions and held for 1 min to equilibrate the system. The injection volumes were 2 $\mu \mathrm{L}$ or $5 \mu \mathrm{L}$ and the column and sample temperatures were $25^{\circ} \mathrm{C}$ and $6{ }^{\circ} \mathrm{C}$, respectively.

(ii) Chromatography was performed with an Acquity UPLC BEH C18 $(50 \times 2.1 \mathrm{~mm}, 1.7$ $\mu \mathrm{m})$ column (Waters), using the same mobile phase and conditions described in method A (i).

Method B used a Q Exactive HF Orbitrap mass spectrometer equipped with a heated electrospray ionization interface (ThermoFisher Scientific) using an Agilent 1200 G1312B binary pump, G1367C autosampler and G1316B column oven (Agilent) connected to a Poroshell SB-C18 HPLC column $(150 \times 2.1 \mathrm{~mm}$ i.d., $2.7 \mu \mathrm{m}$; Agilent $)$ held at $30{ }^{\circ} \mathrm{C}$. Analyses were performed with mobile phases $A$ and $\mathrm{B}$ of $\mathrm{H}_{2} \mathrm{O}$ and $\mathrm{CH}_{3} \mathrm{CN}-\mathrm{H}_{2} \mathrm{O}$ (95:5), respectively, each of which contained ammonium formate $(2 \mathrm{mM})$ and formic acid $(50 \mathrm{mM})$. Gradient elution $(0.275$ $\mathrm{mL} / \mathrm{min}$ ) was from $5-100 \% \mathrm{~B}$ over $20 \mathrm{~min}$, followed by a hold at 100\% B (25 min), a return to $5 \% \mathrm{~B}$ over $1 \mathrm{~min}$ and a hold at 5\% B (10 min) to equilibrate the column. The MS was operated in positive ion mode and calibrated from $m / z 74-1922$. The spray voltage was $3 \mathrm{kV}$, the capillary temperature was $350{ }^{\circ} \mathrm{C}$, and the sheath and auxiliary gas flow rates were 35 and 10 units respectively. The MS was operated in AIF mode (full scan: scan range $m / z$ 400-1400, resolution 120,000, AGC target $3 \times 10^{6}$, max IT $200 \mathrm{~ms}$; AIF: scan range $\mathrm{m} / \mathrm{z}$ 93-1400, resolution 60,000, AGC target $3 \times 10^{6}$, maximum IT $200 \mathrm{~ms}$, and collision energy $55 \mathrm{~V}$ ) to obtain full scan and allion fragmentation spectra, or in PRM mode (at $m / z$ 810.5, 826.5, 828.5, 842.5, 844.5 and 858.5, as appropriate, with resolution 60,000, AGC target $2 \times 10^{5}$, max IT $100 \mathrm{~ms}$, isolation window 1.0, and collision energies of 55 and $75 \mathrm{~V}$ ) to obtain MS/MS spectra.

ADAM derivatives of $\mathbf{3}$ were analysed using an Agilent 1200 LC system connected to a Sciex API4000 QTRAP mass spectrometer equipped with a Turbospray ionization source. LC-FLD measurements were on an Agilent 1290 LC system equipped with a fluorescence detector (model no. G4212A). A $3.5 \mu \mathrm{m}$ Zorbax Eclipse Plus C8 column $(2.1 \times 150 \mathrm{~mm})$ (Agilent Technologies, Mississauga, Ontario, Canada), was eluted isocratically with $85 \% \mathrm{CH}_{3} \mathrm{CN}$ containing $5 \mathrm{mM}$ ammonium acetate at $300 \mu \mathrm{L} / \mathrm{min}$. The FLD detector was operated with excitation at $254 \mathrm{~nm}$ and 
emission at $412 \mathrm{~nm}$. Injection volumes of $5 \mu \mathrm{L}$ were used and the column was maintained at $+20{ }^{\circ} \mathrm{C}$.

Isolation and Purification of 3. The isolation procedure was reported previously. ${ }^{16}$ Due to the presence of co-eluting compounds two additional semi-preparative steps using $\mathrm{CH}_{3} \mathrm{CN} / \mathrm{H}_{2} \mathrm{O}$ (0.8:1, plus $2 \mathrm{mM}$ ammonium acetate) were required to attain sufficient purity for NMR. Purified 3 was recovered by diluting the fractions with $\mathrm{H}_{2} \mathrm{O}$ (to $20 \% \mathrm{CH}_{3} \mathrm{CN}$ ), loading on to solid-phase extraction (SPE) cartridges (Oasis $\mathrm{HLB}, 200 \mathrm{mg}$ ), washing with $\mathrm{MeOH} / \mathrm{H}_{2} \mathrm{O}(1: 9,10 \mathrm{~mL}$ ) to remove the buffer, and eluting with $\mathrm{MeOH} / \mathrm{H}_{2} \mathrm{O}(9: 1,20 \mathrm{~mL})$. Removal of solvent by evaporation in vacuo afforded purified $\mathbf{3}(34 \mu \mathrm{g})$ as a white solid.

AZA26 (3): white, amorphous solid; $\lambda_{\max } 266 \mathrm{~nm} ;{ }^{1} \mathrm{H}(600 \mathrm{MHz})$ and ${ }^{13} \mathrm{C}(150 \mathrm{MHz})$ data $\left(\mathrm{CD}_{3} \mathrm{OH}\right)$, Table 1; HRESIMS $m / z$ 824.4576 [M+H] ${ }^{+}\left(\right.$calcd for $\mathrm{C}_{46} \mathrm{H}_{66} \mathrm{NO}_{12}{ }^{+}, 824.4585$ ).

Analysis of Hepatopancreas Extracts. Homogenised hepatopancreas samples (5 g dissected from cooked and raw AZA contaminated M. edulis, collected from the Northwest of Ireland in 2005 and 2006) were extracted with $\mathrm{MeOH}$ by vortex mixing for 1 min with $4 \mathrm{~mL}$ of $\mathrm{MeOH}$, centrifuged at 3,950 $\mathrm{g}(5 \mathrm{~min})$, and the supernatant decanted into a $10 \mathrm{~mL}$ volumetric flask. The remaining pellet was further extracted using an Ultra Turrax (IKA) for 1 min with an additional $4 \mathrm{~mL}$ of $\mathrm{MeOH}$, centrifuged at 3,950 $\times \mathrm{g}, 5 \mathrm{~min}$, the supernatant decanted into the same $10 \mathrm{~mL}$ volumetric flask and made up to volume with $\mathrm{MeOH}$. An aliquot of the sample was passed through a Whatman $0.2 \mu \mathrm{m}$ cellulose acetate filter into an HPLC vial for analysis.

Periodate Cleavage. Dilutions ( 60 ng/mL) of purified 1 and 3 in MeOH were used. To $100 \mu \mathrm{L}$ of each sample was added $50 \mu \mathrm{L}$ of $0.2 \mathrm{M}$ sodium periodate solution, and the reactions analyzed immediately by LC-MS (method A (ii)) including traces at $\mathrm{m} / \mathrm{z}, 448.4$ (for the oxidation products). Additionally, to $150 \mu \mathrm{L}$ of the cooked hepatopancreas extract, $20 \mu \mathrm{L}$ of a $0.5 \mathrm{M}$ sodium periodate solution was added and the reaction analysed by LC-MS (method A (i and ii)).

Stability Studies. Purified samples of $\mathbf{3}$ (in $\mathrm{MeOH}$ ) were stored in flame-sealed ampoules (under nitrogen) at $-18{ }^{\circ} \mathrm{C},+20{ }^{\circ} \mathrm{C}$ and $+40{ }^{\circ} \mathrm{C}$ for up to 7 days. The study was performed isochronously, ${ }^{31}$ and samples were analyzed simultaneously by LC-MS (method A (ii)). Samples stored at $-80{ }^{\circ} \mathrm{C}$ were used as controls.

Aliquots of an equimolar mixture of $\mathbf{1}$ and AZA3 $\mathrm{CRMs}^{28}$ were gently evaporated to dryness under a stream of nitrogen and reconstituted in $\mathrm{MeOH}$ or in $\mathrm{MeOH}$ containing $0.05 \% \mathrm{v} / \mathrm{v}$ $\mathrm{HCO}_{2} \mathrm{H}$. Aliquots $(250 \mu \mathrm{L})$ were dispensed in amber glass ampoules and stored at $+60{ }^{\circ} \mathrm{C}$ for 
periods of $1,2,4,7$, and 14 days. Samples were then stored at $-80^{\circ} \mathrm{C}$ before transferring to vials for LC-HRMS analysis (method B).

Aliquots from pure AZA4, $-5,-6,-9$ and -10 reference materials (RMs) ${ }^{19}$ were similarly transferred to ampoules in $\mathrm{MeOH}$ or $\mathrm{MeOH}$ containing $0.05 \% \mathrm{v} / \mathrm{v} \mathrm{HCO}_{2} \mathrm{H}$ and heated at $60{ }^{\circ} \mathrm{C}$ for 1 day, followed by storage and analysis as described above for 1 and AZA3. An AZA7 RM contaminated with AZA5 and an AZA with $\mathrm{m} / \mathrm{z}$ 826.5, available from earlier work, ${ }^{19}$ was used for comparison with the AZA4 RM.

\section{9-Anthryldiazomethane (ADAM) Derivatisation}

Solutions of 9-anthraldehyde hydrazone $(35 \mathrm{mM}), N$-chlorosuccinimide $(35 \mathrm{mM})$ and quinuclidine $(70 \mathrm{mM})$ were prepared in THF, combined 1:1:1, and allowed react at room temperature in the dark for $60 \mathrm{~min}$ before use. Based on preliminary measurements of 3 by LCMS with single ion monitoring (SIM), an equimolar mixture of purified $\mathbf{3}$ and CRM-AZA2 was prepared.

A $75 \mu \mathrm{L}$ aliquot of the sample was placed in a $2 \mathrm{~mL}$ amber vial with $200 \mu \mathrm{L}$ of the ADAM derivatising reagent. The reaction mixture was placed in a sonication bath for $10 \mathrm{~min}$ at $37^{\circ} \mathrm{C}$ and then transferred to an oven at $37^{\circ} \mathrm{C}$ for $2.5 \mathrm{~h}$. Samples were then dried using a rotary vacuum drier.

ADAM-derivatised samples were cleaned following the previously described method. ${ }^{27}$ Briefly, activated silica was packed into $7 \mathrm{~mL}$ glass SPE tubes and conditioned using $6 \mathrm{~mL}$ of $\mathrm{CHCl}_{3}$ followed by $6 \mathrm{~mL}$ of hexane- $\mathrm{CHCl}_{3}(1: 1)$. The dried ADAM-derivatised samples were dissolved in $3 \times 300 \mu \mathrm{L}$ of hexane- $\mathrm{CHCl}_{3}(1: 1)$ and passed slowly through the column $(\sim 1 \mathrm{drop} / \mathrm{s})$. The columns were washed with $7 \mathrm{~mL}$ of hexane- $\mathrm{CHCl}_{3}$ (1:1) followed by $8 \mathrm{~mL}$ of $\mathrm{CHCl}_{3}$ (adjusted to contain $1.2 \% \mathrm{EtOH})$. Samples were eluted with $5 \mathrm{~mL}$ of $\mathrm{MeOH}-\mathrm{CHCl}_{3}$ (3:7). The eluate was evaporated to dryness under nitrogen and reconstituted in $200 \mu \mathrm{L} \mathrm{MeOH}$.

NMR Experiments. Structures were determined by analysis of ${ }^{1} \mathrm{H}$, COSY, TOCSY, SELTOCSY, NOESY, ROESY, HSQC and HMBC, ${ }^{13} \mathrm{C}$ and DEPT135 NMR spectra. A sample of $3(34 \mu \mathrm{g})$ was dissolved in $\sim 0.6 \mathrm{~mL}$ of $\mathrm{CD}_{3} \mathrm{OH}$ at $30{ }^{\circ} \mathrm{C}$, and chemical shifts were referenced to internal $\mathrm{CHD}_{2} \mathrm{OH}$ (3.31 ppm) or $\mathrm{CD}_{3} \mathrm{OH}$ (49.0 ppm). Single- or double-frequency presaturation of solvent resonances was performed using continuous wave and/or excitation sculpting, as required. NMR data for $\mathbf{4}$ were obtained by examination of existing NMR spectra of 
a contaminated sample containing a mixture of AZA7 $(93 \mu \mathrm{g}), 4(30 \mu \mathrm{g})$, AZA5 (20 $\mu \mathrm{g})$ and 37epi-AZA7 $(4 \mu \mathrm{g}){ }^{19}$

Toxins and Other Materials. All solvents (pesticide analysis grade) were from Labscan and Caledon. Distilled $\mathrm{H}_{2} \mathrm{O}$ was further purified using a Barnstead nanopure diamond UV purification system (Thermo Scientific) or a Milli-Q water purification system (Millipore Ltd.). Sodium chloride $(99+\%)$, triethylamine $(99 \%)$, ammonium acetate $(97+\%)$, ammonium formate (reagent grade), formic acid (>98\%), $N$-chlorosuccinimide (>98\%), quinuclidine (97\%), 9anthrylaldehye, hydrazone hydrate, silica gel (10-40 $\mu \mathrm{m}$, type H), sodium chloride (99+\%), and sodium periodate were from Sigma-Aldrich. Silica gel 60 was from Merck. Sephadex LH-20 was from GE Healthcare, LiChroprep RP C8 (25-40 $\mu \mathrm{m})$ was from Merck, Luna phenyl-hexyl $(15 \mu \mathrm{m})$ was from Phenomenex. AZA CRMs were from the National Research Council of Canada.

Toxicology. Cell Culturing. Human Jurkat E6-1 T lymphocyte cells (American Type Culture Collection TIB-152) were grown as described by Twiner et al. ${ }^{29}$ Briefly, cells were grown in RPMI medium (cat. \#11875-093, Invitrogen) supplemented with 10\% (v/v) fetal bovine serum (FBS; cat. \#26140, Invitrogen) and maintained in a humidified incubator (Sanyo 18AIC-UV) with $5 \% \mathrm{CO}_{2}$ in air at $37{ }^{\circ} \mathrm{C}$. Cells were subcultured with fresh medium at an inoculum ratio of 1:4 every 3 to 4 days by transferring $2.5 \mathrm{~mL}$ of cells to $7.5 \mathrm{~mL}$ of fresh supplemented medium in $75 \mathrm{~cm}^{3}$ screw cap culture flasks.

Cytotoxicity Assay. Jurkat T lymphocyte cells were continuously exposed to $\mathbf{1}$ and $\mathbf{3}$ and viability determined. The non-adherent human cell line Jurkat T lymphocyte (ATCC cat. \# TIB-152) was grown in RPMI medium supplemented with $10 \%$ (v/v) FBS. Cells were maintained in humidified $5 \% \mathrm{CO}_{2}$ in air at $37{ }^{\circ} \mathrm{C}$ and subcultured with fresh medium at an inoculum ratio of 1:10 every 5 to 7 days by transferring $1 \mathrm{~mL}$ of cells to $9 \mathrm{~mL}$ of fresh supplemented medium in 75 $\mathrm{cm}^{2}$ screw cap culture flasks. Cells were seeded in a volume of $100 \mu \mathrm{L}$ of the supplemented medium at a density of 35,000 cells per well in black, sterile, 96-well culture plates for $24 \mathrm{~h}$ to allow for recovery and settling. Each AZA was added at a single concentration (10 $\mathrm{mM})$ for 24 , 48 , or $72 \mathrm{~h}$ of continuous exposure prior to assessment of cytotoxicity. Parallel controls of equivalent amounts of $\mathrm{MeOH} /$ phosphate-buffered saline were used to normalize the viability data for each treatment. Cellular viability/cytotoxicity was assessed using the 3-(4,5dimethylthiazol-2-yl)-5-(3-carboxymethoxyphenyl)-2-(4-sulfophenyl)-2H-tetrazolium assay (Promega Biosciences). Like other tetrazolium-based assays, MTS in the presence of an 
electron coupling reagent (phenazinemethosulfate (PMS)) measures cellular viability by determining the activity of mitochondrial dehydrogenase. ${ }^{32}$

As a substrate for dehydrogenases, MTS becomes reduced to a soluble, purple dye that can be quantitated colourimetrically to determine the relative level of cellular viability/cytotoxicity per well. Following exposure of the cells to the AZA analogues for the specified period of time, each well received $10 \mu \mathrm{L}$ of a PMS/MTS (1:20) solution. Cells were incubated for $4 \mathrm{~h}$, after which, absorbance readings at $485 \mathrm{~nm}$ were obtained using a FluoStar microplate reader (BMG Lab Technologies). Data are presented as means \pm SE of three separate experiments. In addition, each cytotoxicity experiment was performed using duplicate wells. Cytotoxicity data were blankcorrected and normalized to the control (\% viability) and plotted using GraphPadPrism (ver. 5.0c). 


\section{ASSOCIATED CONTENT}

\section{Supporting Information}

Chemistry of periodate cleavage of AZAs; AZA26 stability data; LC-MS analysis of a cooked hepatopancreas extract after treatment with periodate; HPLC chromatograms after ADAM derivatisation; NMR spectra of AZA26 and AZA48; LC-HRMS/MS chromatograms and mass spectra from heated samples of AZA1, -3, -4, -5, -6, -9 and -10 and cooked mussel hepatopancreas extract; structural changes occurring during interconversions of AZAs.

The Supporting Information is available free of charge on the ACS Publications website at DOI:

\section{AUTHOR INFORMATION}

\section{Corresponding author}

*Tel: (+353) 91 387376. Fax: (+353) 91 387201. Email: jane.kilcoyne@ marine.ie

\section{Notes}

The authors declare no competing financial interest.

\section{ACKNOWLEDGEMENT}

This project, ASTOX 2, (PBA/AF/08/001(01) was carried out under the Sea Change strategy with the support of the Marine Institute and the Marine Research Sub-Programme of the National Development Plan 2007-2013, co-financed under the European Regional Development Fund and supported in part by a Marie Curie International Incoming Fellowship (to C.O.M.) within the seventh European Community Framework Programme (FP7/2007-2013) under grant agreement no. 221117, and by the First Call for Transnational Research Projects within the Marine Biotechnology ERA-NET; project no. 604814. ("Enhanced Biorefining Methods for the Production of Marine Biotoxins and Microalgae Fish Feed"). 


\section{REFERENCES}

(1) Satake, M., Ofuji, K., Naoki, H., James, K. J., Furey, A., McMahon, T., Silke, J., and Yasumoto, T. J. Am. Chem. Soc. 1998, 120, 9967-9968.

(2) Ofuji, K., Satake, M., McMahon, T., Silke, J., James, K. J., Naoki, H., Oshima, Y., and Yasumoto, T. Nat. Toxins 1999, 7, 99-102.

(3) Ofuji, K., Satake, M., McMahon, T., James, K. J., Naoki, H., Oshima, Y., and Yasumoto, T. Biosci. Biotechnol. Biochem. 2001, 65, 740-742.

(4) Rehmann, N., Hess, P., and Quilliam, M. A. Rapid Commun. Mass Spectrom. 2008, 22, 549-558.

(5) Kilcoyne, J., Jauffrais, T., Twiner, M., Doucette, G., Aasen Bunæs, J. A., Sosa, S., Krock, B., Séchet, V., Nulty, C., Salas, R., Clarke, D., Geraghty, J., Duffy, C., Foley, B., John, U., Quilliam, M. A., McCarron, P., Miles, C. O., Silke, J., Cembella, A., Tillmann, U., and Hess, P. Marine Institute Marine Research Sub-Programme (NDP 2007-2013) series (http://oar.marine.ie/handle/10793/970), 2014. Accessed 3 November 2017.

(6) Krock, B., Tillmann, U., Potvin, E., Jeong, H. J., Drebing, W., Kilcoyne, J., Bickmeyer, U., Göthel, Q., and Köck, M. Mar. Drugs 2015, 13, 6687-6702.

(7) Rossi, R., Dell'Aversano, C., Krock, B., Ciminiello, P., Percopo, I., Tillmann, U., Soprano, V., and Zingone, A. Anal. Bioanal. Chem 2017, 409, 1121-1134.

(8) Tillmann, U., Borel, C. M., Barrera, F., Lara, R., Krock, B., Almandoz, G. O., Witt, M., and Trefault, N. Harmful Algae 2016, 51, 40-55.

(9) Kim, J. H., Tillmann, U., Adams, N. G., Krock, B., Stutts, W. L., Deeds, J. R., Han, M. S., and Trainer, V. L. Harmful Algae 2017, 68, 152-167.

(10) Anon. Official Journal of the European Union 2011, L6, 3-6.

(11) Krock, B., Tillmann, U., John, U., and Cembella, A. D. Harmful Algae 2009, 8, 254-263.

(12) Salas, R., Tillmann, U., John, U., Kilcoyne, J., Burson, A., Cantwell, C., Hess, P., Jauffrais, T., and Silke, J. Harmful Algae 2011, 10, 774-783.

(13) Jauffrais, T., Marcaillou, C., Herrenknecht, C., Truquet, P., Séchet, V., Nicolau, E., Tillmann, U., and Hess, P. Toxicon 2012, 60, 582-595.

(14) Kilcoyne, J., McCarron, P., Hess, P., and Miles, C. O. J. Agric. Food Chem. 2015, 63, 10980-10987.

(15) McCarron, P., Kilcoyne, J., Miles, C. O., and Hess, P. J. Agric. Food Chem. 2009, 57, 160-169.

(16) Kilcoyne, J., Keogh, A., Clancy, G., LeBlanc, P., Burton, I., Quilliam, M. A., Hess, P., and Miles, C. O. J. Agric. Food Chem. 2012, 60, 2447-2455.

(17) Kilcoyne, J., McCarron, P., Twiner, M. J., Nulty, C., Wilkins, A. L., Rise, F., Quilliam, M. A., and Miles, C. O. Chem. Res. Toxicol. 2014, 27, 587-600.

(18) Kilcoyne, J., Nulty, C., Jauffrais, T., McCarron, P., Herve, F., Wilkins, A. L., Foley, B., Rise, F., Crain, S., Twiner, M. J., Hess, P., and Miles, C. O. J. Nat. Prod. 2014, 77, 2465-2474.

(19) Kilcoyne, J., Twiner, M. J., McCarron, P., Crain, S., Giddings, S. D., Wilkins, A. L., Hess, P., and Miles, C. O. J. Agric. Food Chem. 2015, 63, 5083-5091.

(20) Twiner, M. J., Hanagriff, J. C., Butler, S., Madhkoor, A. K., and Doucette, G. J. Chem. Res. Toxicol. 2012, 25, 1493-1501.

(21) Twiner, M. J., Doucette, G. J., Rasky, A., Huang, P. X., Roth, B. L., and Sanguinetti, M. C. Chem. Res. Toxicol. 2012, 25, 1975-1984.

(22) Bodero, M., Hoogenboom, R. L. A. P., Bovee, T. F. H., Portier, L., de Haan, L., Peijnenburg, A., and Hendriksen, P. J. M. Toxicol. in vitro 2018, 46, 102-112.

(23) Alfonso, C., Rehmann, N., Hess, P., Alfonso, A., Wandscheer, C., Abuin, M., Vale, C., Otero, P., Vieytes, M., and Botana, L. M. Anal. Chem. 2008, 80, 9672-9680.

(24) Kenton, N. T., Adu-Ampratwum, D., Okumu, A. A., McCarron, P., Kilcoyne, J., Rise, F., Wilkins, A. L., Miles, C. O., and Forsyth, C. J. Angew. Chem. Int. Ed. 2018, 57, 810-813.

(25) Svensson, M., Lundgren, L. N., Woods, C., Fatehi, J., and Stenlid, J. Phytochemistry 2001, 56, 747751. 
(26) Eliel, E. L., Manoharan, M., Pietrusiewicz, K. M., and Hargrave, K. D. Org. Magn. Resonance 1983, 21, 94-107.

(27) McCarron, P., Giddings, S. D., Miles, C. O., and Quilliam, M. A. J. Chromatogr. A 2011, 1218, 80898096.

(28) Perez, R., Rehmann, N., Crain, S., LeBlanc, P., Craft, C., MacKinnon, S., Reeves, K., Burton, I., Walter, J. A., Hess, P., Quilliam, M. A., and Melanson, J. Anal. Bioanal. Chem. 2010, 398, 2243-2252.

(29) Twiner, M. J., El-Ladki, R., Kilcoyne, J., and Doucette, G. J. Chem. Res. Toxicol. 2012, 25, 747-754.

(30) Ito, E., Frederick, M. O., Koftis, T. V., Tang, W., Petrovic, G., Ling, T., and Nicolaou, K. C. Harmful Algae 2006, 5, 586-591.

(31) Lamberty, A., Schimmel, H., and Pauwels, J. J. Anal. Chem. 1998, 360, 359-361.

(32) Mosmann, T. J. Immunol. Methods 1983, 65, 55-63. 
Table 1. NMR Assignments (600 MHz, $\left.\mathrm{CD}_{3} \mathrm{OH}\right)$ for AZA1 (1) and AZA26 (3), and Partial Assignments for AZA48 (4) as a Contaminant in $\mathrm{AZA7}^{a}$

\begin{tabular}{|c|c|c|c|c|c|c|}
\hline \multirow[b]{2}{*}{ Atom } & \multicolumn{2}{|r|}{$\operatorname{AZA1}(\mathbf{1})^{b}$} & \multicolumn{2}{|r|}{ AZA26 (3) } & \multicolumn{2}{|c|}{ AZA48 $(\mathbf{4})^{c}$} \\
\hline & $\delta_{\mathrm{C}}$, type & $\delta_{\mathrm{H}}(J$ in $\mathrm{Hz})$ & $\delta_{\mathrm{C}}$, type & $\delta_{\mathrm{H}}(J$ in $\mathrm{Hz})$ & $\delta_{\mathrm{C}}$, type & $\delta_{\mathrm{H}}(J$ in $\mathrm{Hz})$ \\
\hline 1 & 181.2, C & & $181.4, \mathrm{C}$ & & & \\
\hline 2 & $38.1, \mathrm{CH}_{2}$ & $2.25, \sim \mathrm{t}(7.0)$ & $38.5, \mathrm{CH}_{2}$ & $2.22, \sim \mathrm{t}(\sim 7)$ & & \\
\hline 3 & $30.2, \mathrm{CH}_{2}$ & $2.33, \sim q(7.0)$ & $30.2, \mathrm{CH}_{2}$ & $2.32, \sim \mathrm{q}(\sim 7)$ & & \\
\hline 4 & $133.7, \mathrm{CH}$ & $5.75, \operatorname{dtd}(15.3,6.5,1.0)$ & $133.9, \mathrm{CH}$ & $5.75, \mathrm{dtd}(15.3,6.6,1.0)$ & & \\
\hline 5 & $130.7, \mathrm{CH}$ & $5.44, \operatorname{ddt}(15.4,7.5,1.4)$ & $130.6, \mathrm{CH}$ & $5.43, \operatorname{ddt}(15.3,7.5,1.4)$ & & \\
\hline 6 & $72.5, \mathrm{CH}$ & 4.79 br d (7.7) & $72.4, \mathrm{CH}$ & 4.78, br m & & \\
\hline 7 & $129.4, \mathrm{CH}$ & 5.63 , ddt $(10.4,2.8,1.4)$ & $129.4, \mathrm{CH}$ & 5.63 , ddt $(10.3,2.8,1.4)$ & & \\
\hline 8 & $123.2, \mathrm{CH}$ & $5.73, \operatorname{ddt}(10.3,5.1,2.2)$ & $123.2, \mathrm{CH}$ & $5.73, \operatorname{ddt}(10.3,5.1,2.2)$ & & \\
\hline 9 & $35.7, \mathrm{CH}_{2}$ & 2.12, br d $(16.9)$ & $35.9, \mathrm{CH}_{2}$ & $2.10, \mathrm{~m}$ & & \\
\hline & & 2.46, ddt $(17.7,4.1,2.4)$ & & $2.47, \mathrm{~m}$ & & \\
\hline 10 & 107.3, C & & $107.5, \mathrm{C}$ & & & \\
\hline 11 & $37.5, \mathrm{CH}_{2}$ & 1.97, dd $(13.3,7.1)$ & $37.5, \mathrm{CH}_{2}$ & $1.95, \mathrm{~m}$ & & \\
\hline & & $2.14, \operatorname{td}(12.9,6.9)$ & & $2.15, \mathrm{~m}$ & & \\
\hline 12 & $33.2, \mathrm{CH}_{2}$ & $1.66, \mathrm{dd}(12.4,7.5)$ & $33.2, \mathrm{CH}_{2}$ & $1.64, \mathrm{dd}(13.3,6.4)$ & & \\
\hline & & $2.33, \operatorname{td}(12.0,7.1)$ & & $2.30, \mathrm{~m}$ & & \\
\hline 13 & $111.3, \mathrm{C}$ & & $110.7, \mathrm{C}$ & & & \\
\hline 14 & $31.0, \mathrm{CH}$ & $2.02, \mathrm{~m}$ & $30.8, \mathrm{CH}$ & $2.01, \mathrm{~m}$ & & \\
\hline 14-Me & $16.6, \mathrm{CH}_{3}$ & $0.95, \mathrm{~d}(6.8)$ & $16.7, \mathrm{CH}_{3}$ & $0.937, \mathrm{~d}(6.9)$ & & \\
\hline $15^{d}$ & $32.6, \mathrm{CH}_{2}$ & 1.76, ddd $(14.4,12.7,3.4)$ & $32.4, \mathrm{CH}_{2}$ & $1.75, \mathrm{t}(13.6)$ & & \\
\hline & & 1.85, ddd $(14.5,4.2,1.8)$ & & $1.84, \mathrm{dd}(14.2,6.5)$ & & \\
\hline 16 & 78.2, $\mathrm{CH}$ & $3.88, \mathrm{dt}(3.4,2.4)$ & 78.7, CH & $3.96, \sim q(\sim 2)$ & & $3.92, \mathrm{~m}$ \\
\hline 17 & $73.3, \mathrm{CH}$ & $4.23, \mathrm{dd}(3.5,1.9)$ & $73.3, \mathrm{CH}$ & $4.22, \mathrm{dd}(4.1,1.1)$ & 73.3, CH & $4.21, \mathrm{~m}$ \\
\hline $18^{e}$ & $37.3, \mathrm{CH}_{2}$ & $1.99,(12.6,6.3)$ & 37.0, $\mathrm{CH}_{2}$ & $1.97, \mathrm{dd}(13.2,6.3)$ & & $1.99, \mathrm{~m}$ \\
\hline & & 2.01, ddd $(13.3,9.0,3.7)$ & & 2.04, ddd $(13.2,9.3,4.1)$ & & \\
\hline 19 & 79.2, $\mathrm{CH}$ & 4.43, ddd $(9.0,6.8,5.5)$ & $80.7, \mathrm{CH}$ & $4.37, \mathrm{dt}(9.3,6.3)$ & $81.2, \mathrm{CH}$ & $4.32, \mathrm{dt}(8.3,6.7)$ \\
\hline 20 & $76.9, \mathrm{CH}$ & $3.86, \mathrm{~d}(5.5)$ & $75.3, \mathrm{CH}$ & $4.08, \mathrm{~d}(6.3)$ & $76.2, \mathrm{CH}$ & $3.75, \mathrm{~d}(6.5)$ \\
\hline 21 & $100.2, \mathrm{C}$ & & 176.7, C & & & \\
\hline 22 & $36.6, \mathrm{CH}$ & $2.12, \mathrm{~m}$ & $103.5, \mathrm{CH}$ & $5.49, \mathrm{~s}$ & $99.5, \mathrm{CH}$ & 4.75, dd $(4.8,2.5)$ \\
\hline 22-Me & $16.4, \mathrm{CH}_{3}$ & $0.91, \mathrm{~d}(6.7)$ & & & & \\
\hline $23^{d}$ & $38.3, \mathrm{CH}_{2}$ & $1.43, \mathrm{~m}$ & $198.1, \mathrm{C}$ & & & 1.80 , dd $(16.4,11.7)$ \\
\hline
\end{tabular}




\begin{tabular}{|c|c|c|c|c|c|c|}
\hline 24 & $42.3, \mathrm{CH}$ & $1.35, \mathrm{~m}$ & $46.3, \mathrm{CH}$ & $2.57, \mathrm{~m}$ & & 1.67, m \\
\hline 24-Me & $18.1, \mathrm{CH}_{3}$ & $0.84, \mathrm{~d}(6.6)$ & $11.0, \mathrm{CH}_{3}$ & $1.06, \mathrm{~d}(7.1)$ & $16.6, \mathrm{CH}_{3}$ & $0.93, \mathrm{~d}(6.3)$ \\
\hline 25 & 79.6, CH & 3.98, d (9.6) & $88.1, \mathrm{CH}$ & $4.61, \mathrm{dd}(11.7,0.8)$ & $84.8, \mathrm{CH}$ & $3.87, \mathrm{~d}(9.1)$ \\
\hline 26 & $148.3, \mathrm{C}$ & & 143.0, C & & 146.1, C & \\
\hline \multirow[t]{2}{*}{$26=\mathrm{CH}_{2}^{f}$} & $116.8, \mathrm{CH}_{2}$ & $5.34, \mathrm{~d}(2.3)$ & $119.1, \mathrm{CH}_{2}$ & $5.47, \mathrm{t}(1.0)$ & 116.0, $\mathrm{CH}_{2}$ & $5.29, \mathrm{~d}(1.7)$ \\
\hline & & $5.16, \mathrm{~d}(2.2)$ & & $5.37, \mathrm{q}(1.0)$ & & $5.19, \mathrm{~d}(1.6)$ \\
\hline \multirow[t]{2}{*}{27} & $49.5, \mathrm{CH}_{2}$ & 2.24, d (13.6) & 47.6, $\mathrm{CH}_{2}$ & $2.23, \mathrm{~d}(14.1)$ & $48.3, \mathrm{CH}_{2}$ & $2.22, \mathrm{~d}(14.2)$ \\
\hline & & $2.41, \mathrm{~d}(14.0)$ & & $2.47, \mathrm{dd}(14.3,0.7)$ & & $2.39, \mathrm{~d}(14.2)$ \\
\hline 28 & 98.6, C & & 98.0, C & & $98.0, \mathrm{C}$ & \\
\hline \multirow[t]{2}{*}{$29^{d}$} & $44.3, \mathrm{CH}_{2}$ & $1.36, \mathrm{dd}(14.4,12.5)$ & $43.6, \mathrm{CH}_{2}$ & $1.39, \mathrm{dd}(14.1,12.5)$ & & \\
\hline & & 2.03, ddd $(14.4,5.5,1.3)$ & & 1.99, dd $(14.6,5.5)$ & & \\
\hline 30 & $26.4, \mathrm{CH}$ & $2.23, \mathrm{~m}$ & $26.8, \mathrm{CH}$ & $2.26, \mathrm{~m}$ & & \\
\hline 30-Me & $23.5, \mathrm{CH}_{3}$ & $0.95, \mathrm{~d}(6.3)$ & $23.9, \mathrm{CH}_{3}$ & $0.939, \mathrm{~d}(6.7)$ & & \\
\hline \multirow[t]{2}{*}{$31^{d}$} & $35.4, \mathrm{CH}_{2}$ & $1.52, \operatorname{ddd}(13.8,13.0,4.7)$ & $35.6, \mathrm{CH}_{2}$ & $1.49, \operatorname{td}(13.5,5.4)$ & & \\
\hline & & 1.83, br d $(13.0)$ & & $1.79, \mathrm{~m}$ & & \\
\hline 32 & $72.8, \mathrm{CH}$ & $4.35, \mathrm{dd}(4.9,1.6)$ & $72.9, \mathrm{CH}$ & $4.31, \mathrm{~d}(4.8)$ & & \\
\hline 33 & $81.2, \mathrm{CH}$ & $4.01, \mathrm{dd}(3.6,0.7)$ & $79.2, \mathrm{CH}$ & $3.74, \mathrm{~d}(3.5)$ & & \\
\hline 34 & $74.9, \mathrm{CH}$ & 4.98, dd $(4.4,3.7)$ & $75.9, \mathrm{CH}$ & $4.82(\mathrm{~m})$ & & \\
\hline \multirow[t]{2}{*}{35} & $41.9, \mathrm{CH}_{2}$ & $2.42, \mathrm{~d}(14.9)$ & $43.0, \mathrm{CH}_{2}$ & $1.81, \mathrm{~d}(14.3)$ & & \\
\hline & & $2.59 \mathrm{dd}(15.0,4.7)$ & & $2.37, \mathrm{dd}(14.2,4.8)$ & & \\
\hline 36 & $96.6, \mathrm{C}$ & & $96.2, \mathrm{C}$ & & & \\
\hline 37 & $38.0, \mathrm{CH}$ & $1.95, \mathrm{~m}$ & $37.8, \mathrm{CH}$ & $1.74, \mathrm{~m}$ & & \\
\hline 37-Me & $15.5, \mathrm{CH}_{3}$ & $0.96, \mathrm{~d}(6.7)$ & $16.1, \mathrm{CH}_{3}$ & $0.87, \mathrm{~d}(6.6)$ & & \\
\hline \multirow[t]{2}{*}{$38^{d}$} & $38.4, \mathrm{CH}_{2}$ & $1.28, \mathrm{dt}(13.4,12.4)$ & $40.0, \mathrm{CH}_{2}$ & $1.14, \mathrm{q}(12.6)$ & & \\
\hline & & $1.67, \operatorname{dtd}(13.5,3.8,1.6)$ & & $1.55, \mathrm{~d}(12.5)$ & & \\
\hline 39 & $29.8, \mathrm{CH}$ & $1.85, \mathrm{~m}$ & $31.7, \mathrm{CH}$ & $1.69, \mathrm{~m}$ & & \\
\hline 39-Me & $18.6, \mathrm{CH}_{3}$ & $0.945, \mathrm{~d}(6.5)$ & $19.7, \mathrm{CH}_{3}$ & $0.86, \mathrm{~d}(6.6)$ & & \\
\hline \multirow[t]{2}{*}{$40^{d}$} & $46.9, \mathrm{CH}_{2}$ & $2.79, \mathrm{t}(12.4)$ & $48.1, \mathrm{CH}_{2}$ & $2.63, \mathrm{t}(11.1)$ & & \\
\hline & & 2.84, br d (12.4) & & 2.59, br d (11.1) & & \\
\hline $40-\mathrm{NH}$ & & 6.35, br s & & & & \\
\hline
\end{tabular}


${ }^{c}$ Obtained by examination of NMR spectra of AZA7 in which AZA48 was a $20 \%$ component. ${ }^{19}$ The remaining resonances of 4 were indistinguishable from those of AZA7.

${ }^{d}$ In the format $\mathrm{H}_{\mathrm{ax}}, \mathrm{H}_{\mathrm{eq}}$.

${ }^{e}$ In the format $\mathrm{H}_{\alpha}, \mathrm{H}_{\beta}$.

${ }^{f}$ In the format $\mathrm{H}_{E}, \mathrm{H}_{Z}$. 
Table 2. Accurate Mass Measurements ( $\Delta$ ppm) and Retention Time Differences (min) Relative to the Precursors of AZA25-28, -48, -49, -60 and -61.

\begin{tabular}{|c|c|c|c|c|c|c|c|c|c|c|c|c|c|}
\hline \multirow[b]{2}{*}{ AZA } & \multicolumn{3}{|c|}{$[\mathrm{M}+\mathrm{H}]^{+}$} & \multicolumn{2}{|c|}{$\left[\mathrm{M}+\mathrm{H}-\mathrm{H}_{2} \mathrm{O}\right]^{+}$} & \multicolumn{3}{|c|}{ Fragment $1^{a}$} & \multicolumn{3}{|c|}{ Fragment $2^{a}$} & \multirow{2}{*}{$\begin{array}{l}\text { Retention time } \\
\text { difference } \\
\text { (method A (i)) }\end{array}$} & \multirow{2}{*}{ Precursor } \\
\hline & $m / z$ & Composition & $\Delta$ & $m / z$ & $\Delta$ & $m / z$ & Composition & $\Delta$ & $m / z$ & Composition & $\Delta$ & & \\
\hline AZA25 & 810.4789 & $\mathrm{C}_{46} \mathrm{H}_{68} \mathrm{NO}_{11}{ }^{+}$ & 0.3 & 792.4665 & -1.4 & 658.3940 & $\mathrm{C}_{37} \mathrm{H}_{56} \mathrm{NO}_{9}^{+}$ & -1.5 & 448.3053 & $\mathrm{C}_{26} \mathrm{H}_{42} \mathrm{NO}_{5}^{+}$ & -1.1 & 0.52 & AZA3 \\
\hline AZA48 (4) & 826.4749 & $\mathrm{C}_{46} \mathrm{H}_{68} \mathrm{NO}_{12}{ }^{+}$ & 1.6 & 808.4630 & 0.6 & 658.3964 & $\mathrm{C}_{37} \mathrm{H}_{56} \mathrm{NO}_{10}{ }^{+}$ & 2.2 & 448.3054 & $\mathrm{C}_{26} \mathrm{H}_{42} \mathrm{NO}_{5}^{+}$ & -0.8 & 0.32 & AZA4 \\
\hline AZA26 (3) & 824.4576 & $\mathrm{C}_{46} \mathrm{H}_{66} \mathrm{NO}_{12}{ }^{+}$ & -0.4 & 806.4468 & -0.1 & 672.3707 & $\mathrm{C}_{37} \mathrm{H}_{54} \mathrm{NO}_{10}{ }^{+}$ & -5.2 & 462.2845 & $\mathrm{C}_{26} \mathrm{H}_{40} \mathrm{NO}_{6}^{+}$ & -1.1 & 0.00 & AZA60 \\
\hline AZA27 & 824.4940 & $\mathrm{C}_{47} \mathrm{H}_{70} \mathrm{NO}_{11}^{+}$ & -0.4 & 806.4827 & -0.7 & 658.3989 & $\mathrm{C}_{37} \mathrm{H}_{56} \mathrm{NO}_{9}^{+}$ & 6.0 & ND & - & & 0.52 & AZA6 \\
\hline AZA49 & 840.4872 & $\mathrm{C}_{47} \mathrm{H}_{70} \mathrm{NO}_{12}{ }^{+}$ & -2.5 & 822.4790 & 1.0 & 658.3956 & $\mathrm{C}_{37} \mathrm{H}_{56} \mathrm{NO}_{9}^{+}$ & 1.0 & 448.3061 & $\mathrm{C}_{26} \mathrm{H}_{42} \mathrm{NO}_{5}^{+}$ & 0.7 & 0.32 & AZA9 \\
\hline AZA28 & 838.4742 & $\mathrm{C}_{47} \mathrm{H}_{68} \mathrm{NO}_{12}{ }^{+}$ & 0.7 & 820.4581 & -5.4 & 672.3747 & $\mathrm{C}_{37} \mathrm{H}_{54} \mathrm{NO}_{10}{ }^{+}$ & 0.7 & $444.2740^{b}$ & $\mathrm{C}_{26} \mathrm{H}_{38} \mathrm{NO}_{5}^{+}$ & -1.1 & 0.00 & AZA61 \\
\hline AZA60 & 826.4717 & $\mathrm{C}_{46} \mathrm{H}_{68} \mathrm{NO}_{12}{ }^{+}$ & -2.3 & 808.4659 & 3.5 & 674.3901 & $\mathrm{C}_{37} \mathrm{H}_{56} \mathrm{NO}_{10}{ }^{+}$ & 0.3 & 464.3009 & $\mathrm{C}_{26} \mathrm{H}_{42} \mathrm{NO}_{6}^{+}$ & 0.5 & -0.24 & AZA5 \\
\hline AZA61 & 840.4880 & $\mathrm{C}_{47} \mathrm{H}_{70} \mathrm{NO}_{12}{ }^{+}$ & -1.5 & 822.4747 & -4.9 & 674.3900 & $\mathrm{C}_{37} \mathrm{H}_{56} \mathrm{NO}_{10}{ }^{+}$ & 0.2 & $446.2893^{b}$ & $\mathrm{C}_{26} \mathrm{H}_{40} \mathrm{NO}_{5}^{+}$ & -1.7 & -0.24 & AZA10 \\
\hline
\end{tabular}

${ }^{a}$ See Figure 1. ${ }^{\Delta}$ All accurate masses for fragment 3 from all the compounds corresponded to within 2.1 ppm for $\mathrm{C}_{22} \mathrm{H}_{36} \mathrm{O}_{3} \mathrm{~N}^{+}(m / z 362.2690)$.

${ }^{b}$ Corresponds to $\mathrm{H}_{2} \mathrm{O}$ loss from fragment 2 . 
Table 3. Calculated $\mathrm{EC}_{50}$ Values (with 95\% Confidence Intervals) and Relative Potencies for AZA1 (1) and -26 (3) Based on a T Lymphocyte Cytotoxicity Assay.

\begin{tabular}{ccc}
\hline \hline \multirow{2}{*}{ AZA analogue } & \multicolumn{2}{c}{$24 \mathrm{~h}$} \\
\cline { 2 - 3 } & $\mathrm{EC}_{50}$ & $95 \% \mathrm{CI}$ \\
\hline AZA1 (1) & 0.5 & $0.18-1.4$ \\
AZA26 (3) & 24 & $5.0-110$
\end{tabular}

\begin{tabular}{cc}
\hline \hline & $48 \mathrm{~h}$ \\
\hline $\mathrm{EC}_{50}$ & $95 \% \mathrm{CI}$ \\
\hline 0.9 & $0.5-1.6$ \\
39 & $18-87$
\end{tabular}

\begin{tabular}{cc}
\hline \hline & $72 \mathrm{~h}$ \\
\hline $\mathrm{EC}_{50}$ & $95 \% \mathrm{CI}$ \\
\hline 0.9 & $0.5-1.5$ \\
30 & $19-48$
\end{tabular}

\begin{tabular}{cc}
\hline \hline $\begin{array}{c}\text { Mean } \\
\mathrm{EC}_{50}\end{array}$ & Relative \\
& Potency \\
\hline 0.8 & 1.00 \\
31 & 0.03
\end{tabular}

(4)




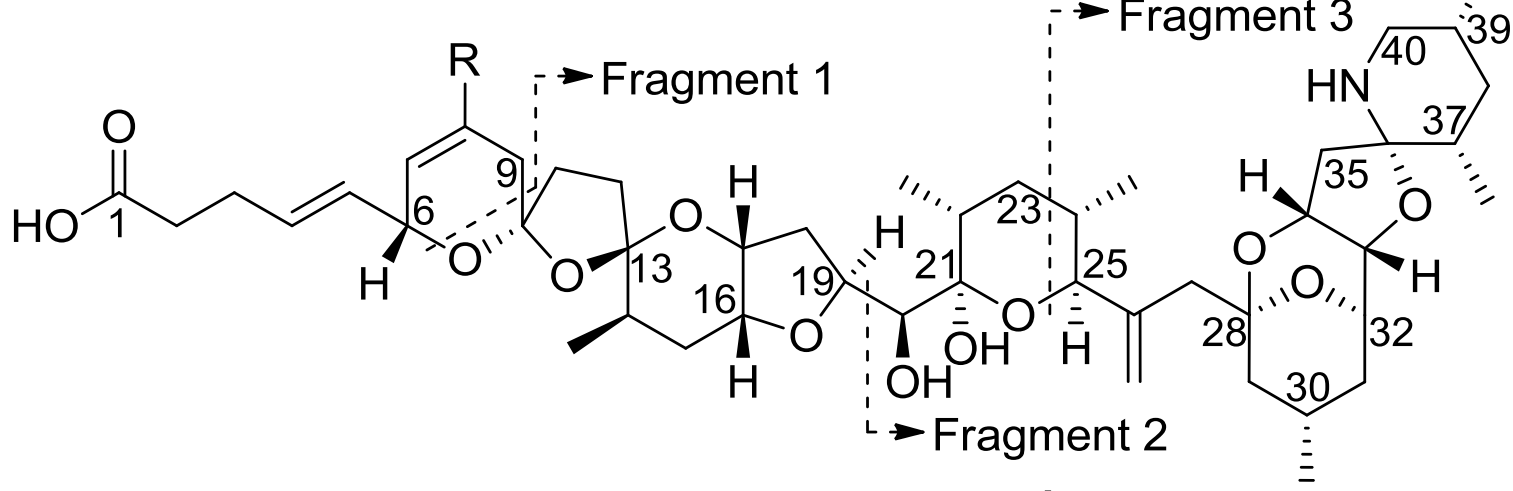

$$
\begin{array}{ll}
\mathrm{R}=\mathrm{H} & \mathrm{AZA1}(1) \\
\mathrm{R}=\mathrm{CH}_{3} & \mathrm{AZA2}(2)
\end{array}
$$

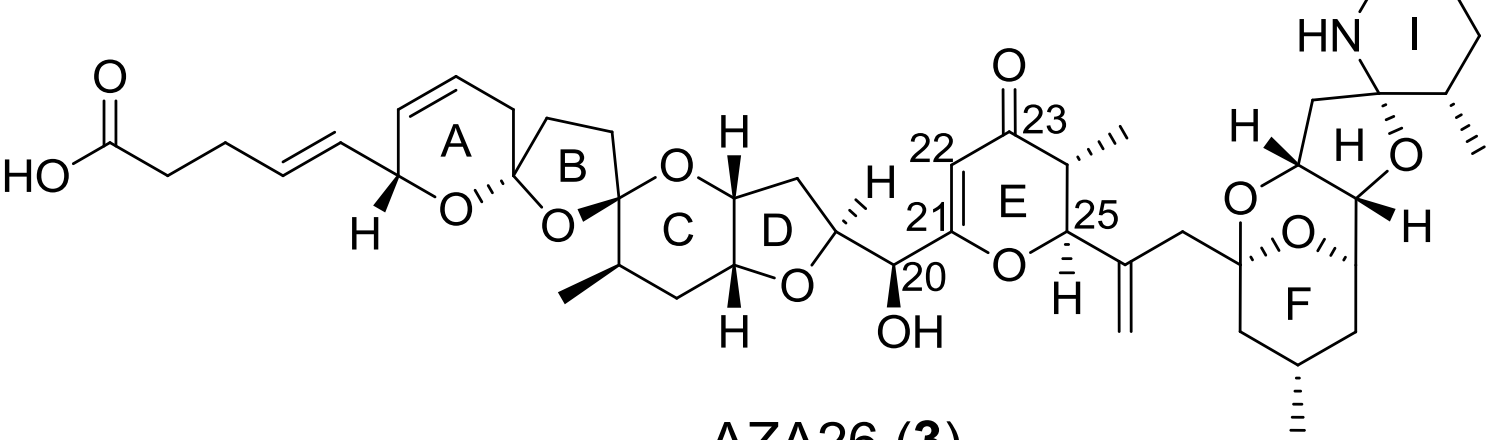

\section{AZA26 (3)}

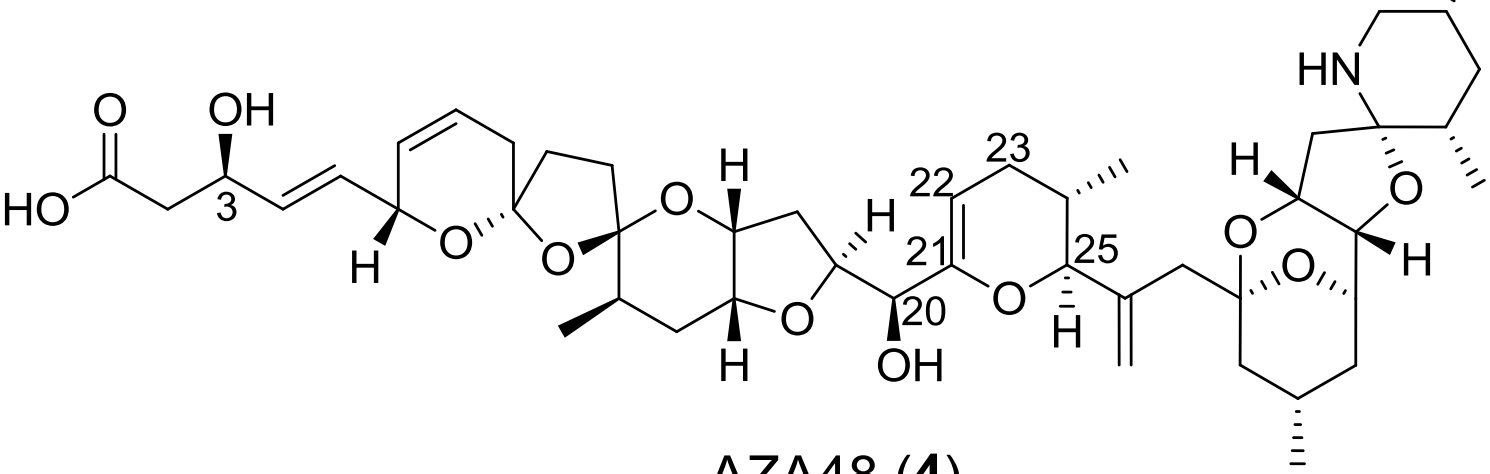



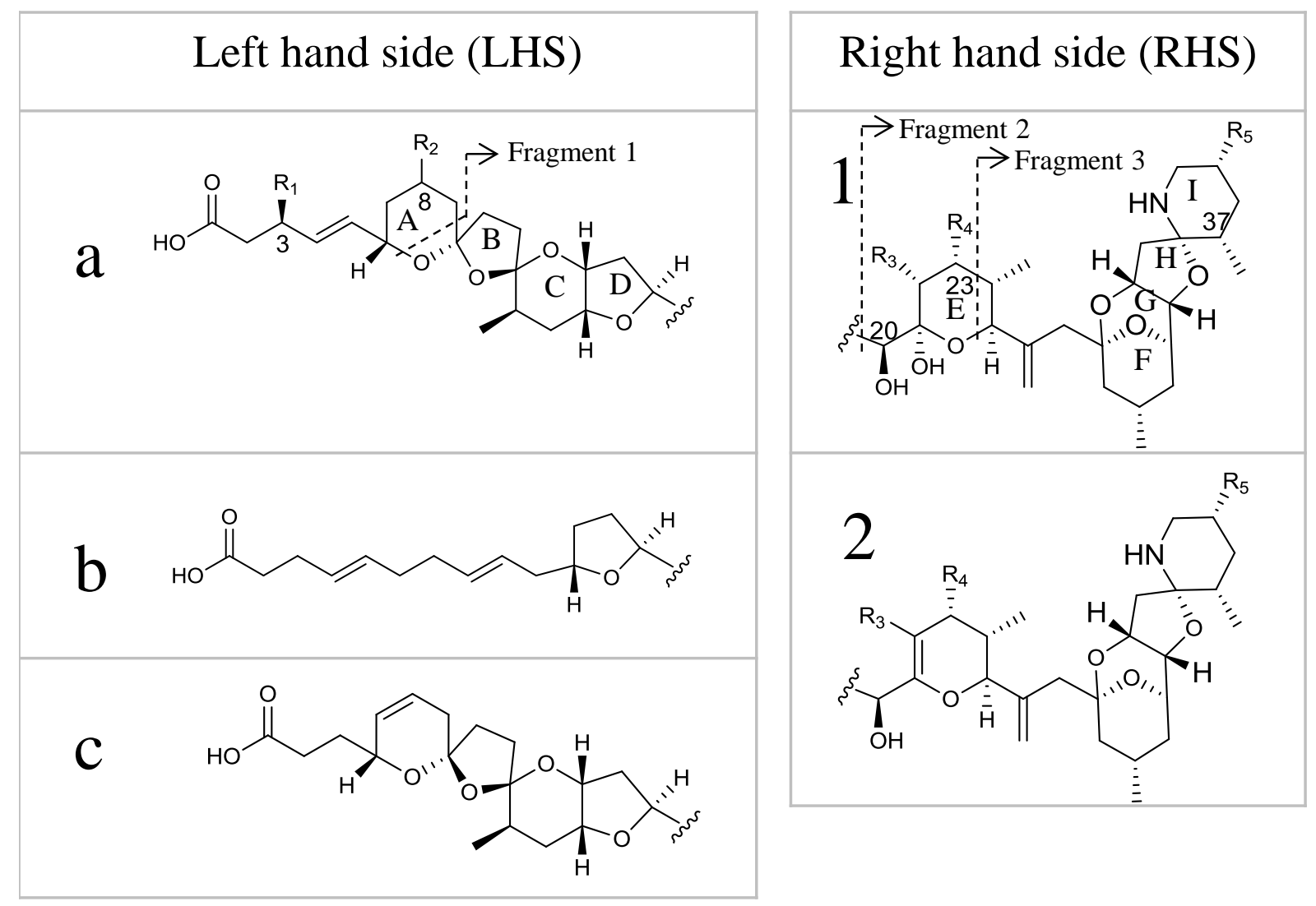

$$
\begin{array}{|l|l|l|l|l|l|l|}
\hline \text { Type }^{\S} & 7,8 & \mathrm{R}_{1} & \mathrm{R}_{2} & \mathrm{R}_{3} & \mathrm{R}_{4} & \mathrm{R}_{5} \\
\hline
\end{array}
$$

\begin{tabular}{|l|}
\hline AZA1 (1) \\
"37-epi-AZA1 \\
\hline AZA2 (2) \\
AZA3 \\
AZA4 \\
AZA5 \\
AZA6 \\
AZA7 \\
AZA8 \\
AZA9 \\
\hline AZA10 \\
\hline AZA11 \\
\hline AZA12 \\
\hline AZA13 \\
\hline AZA14 \\
\hline AZA15 \\
\hline AZA16 \\
\hline AZA17 \\
\hline AZA19 \\
\hline AZA21 \\
\hline AZA23 \\
\hline AZA25 \\
\hline AZA26 $(3)$ \\
\hline AZA27 \\
\hline AZA28 \\
\hline AZA33 \\
AZA34 \\
\hline AZA36 \\
\hline AZA37 \\
\hline AZA44 \\
AZA45 \\
\hline AZA46 \\
\hline AZA47 \\
\hline
\end{tabular}

$\begin{array}{ll}\text { a1 } & \Delta \\ \text { a1 } & \Delta \\ \text { a1 } & \Delta \\ \text { a1 } & \Delta \\ \text { a1 } & \Delta \\ \text { a1 } & \Delta \\ \text { a1 } & \Delta \\ \text { a1 } & \Delta \\ \text { a1 } & \Delta \\ \text { a1 } & \Delta \\ \text { a1 } & \Delta \\ \text { a1 } & \Delta \\ \text { a1 } & \Delta \\ \text { a1 } & \Delta \\ \text { a1 } & \Delta \\ \text { a1 } & \Delta \\ \text { a1 } & \Delta \\ \text { a1 } & \Delta \\ \text { a1 } & \Delta \\ \text { a1 } & \Delta \\ \text { a1 } & \Delta \\ \text { a2 } & \Delta \\ \text { a2 } & \Delta \\ \text { a2 } & \Delta \\ \text { a2 } & \Delta \\ \text { b1 } & \Delta \\ \text { c1 } & \Delta \\ \text { a1 } & \Delta \\ \text { a1 } & \\ \text { a1 } & \\ \text { a1 } & \Delta \\ \text { a1 } & \Delta \\ \text { a1 } & \Delta \\ & \end{array}$

$\begin{array}{ccccc}\Delta & \mathrm{H} & \mathrm{H} & \mathrm{CH}_{3} & \\ \Delta & \mathrm{H} & \mathrm{H} & \mathrm{CH}_{3} & \\ \Delta & \mathrm{H} & \mathrm{CH}_{3} & \mathrm{CH}_{3} & \\ \Delta & \mathrm{H} & \mathrm{H} & \mathrm{H} & \\ \Delta & \mathrm{OH} & \mathrm{H} & \mathrm{H} & \\ \Delta & \mathrm{H} & \mathrm{H} & \mathrm{H} & \mathrm{OH} \\ \Delta & \mathrm{H} & \mathrm{CH}_{3} & \mathrm{H} & \\ \Delta & \mathrm{OH} & \mathrm{H} & \mathrm{CH}_{3} & \\ \Delta & \mathrm{H} & \mathrm{H} & \mathrm{CH}_{3} & \mathrm{OH} \\ \Delta & \mathrm{O} & \mathrm{CH}_{3} & \mathrm{H} & \end{array}$

$\begin{array}{lll}\mathrm{H} & \mathrm{CH}_{3} & 842.5049\end{array}$

$\begin{array}{ll}\mathrm{CH}_{3} & 842.5049\end{array}$

$\begin{array}{ll}\mathrm{CH}_{3} & 856.5206 \\ \mathrm{CH}_{3} & 828.4893\end{array}$

\begin{tabular}{lll}
$\mathrm{CH}_{3}$ & 828.4893 \\
\hline
\end{tabular}

$\begin{array}{lll}\mathrm{H} & \mathrm{CH}_{3} & 844.4842\end{array}$

$\begin{array}{lll}\mathrm{OH} & \mathrm{CH}_{3} & 844.4842\end{array}$

$\begin{array}{lll}\mathrm{CH}_{3} & 842.5049\end{array}$

$\begin{array}{lll}\mathrm{H} & \mathrm{CH}_{3} & 858.4998\end{array}$

$\begin{array}{lll}\mathrm{OH} & \mathrm{CH}_{3} & 858.4998\end{array}$

$\begin{array}{lllllll}\Delta & \mathrm{OH} & \mathrm{CH}_{3} & \mathrm{H} & \mathrm{H} & \mathrm{CH}_{3} & 858.4998\end{array}$

$\Delta \quad \mathrm{H} \quad \mathrm{CH}_{3}$

$\mathrm{H} \quad \mathrm{OH}$

$\mathrm{OH} \quad \mathrm{CH}_{3}$

\begin{tabular}{ll}
$\mathrm{CH}_{3}$ & 858.4998 \\
\hline
\end{tabular}

\begin{tabular}{llllllll}
$\Delta$ & $\mathrm{OH}$ & $\mathrm{CH}_{3}$ & $\mathrm{CH}_{3}$ & $\mathrm{H}$ & $\mathrm{CH}_{3}$ & 872.5155 \\
\hline
\end{tabular}

\begin{tabular}{l|l|l|l|lll|l}
\hline$\Delta$ & $\mathrm{H}$ & $\mathrm{CH}_{3}$ & $\mathrm{CH}_{3}$ & $\mathrm{OH}$ & $\mathrm{CH}_{3}$ & 872.5155
\end{tabular}

\begin{tabular}{l|l|l|l|l|l|l}
$\Delta$ & $\mathrm{OH}$ & $\mathrm{H}$ & $\mathrm{H}$ & $\mathrm{OH}$ & $\mathrm{CH}_{3}$ & 860.4791
\end{tabular}

$\begin{array}{llllllll}\Delta & \mathrm{OH} & \mathrm{H} & \mathrm{CH}_{3} & \mathrm{OH} & \mathrm{CH}_{3} & 874.4947\end{array}$

$\begin{array}{llllllll}\Delta & \mathrm{OH} & \mathrm{CH}_{3} & \mathrm{H} & \mathrm{OH} & \mathrm{CH}_{3} & 874.4947\end{array}$

$\Delta$

$\mathrm{OH} \quad \mathrm{CH}_{3}$

$\mathrm{OH}$

\begin{tabular}{l|l}
$\mathrm{CH}_{3}$ & 874.4947 \\
$\mathrm{CH}_{3}$ & 888.5104
\end{tabular}

$\begin{array}{lllllll}\Delta & \mathrm{H} & \mathrm{H} & \mathrm{CO}_{2} \mathrm{H} & \mathrm{H} & \mathrm{CH}_{3} & 872.4791\end{array}$

$\Delta$

$\mathrm{H} \quad \mathrm{CH}_{3}$

$\mathrm{CO}_{2} \mathrm{H}$

$\mathrm{H}$

$\Delta \quad \mathrm{OH}$

$\begin{array}{ll}\mathrm{CH}_{3} & 886.4947\end{array}$

$\Delta$

$\begin{array}{ccccccc}\Delta & \mathrm{OH} & \mathrm{CH}_{3} & \mathrm{CO}_{2} \mathrm{H} & \mathrm{H} & \mathrm{CH}_{3} & 902.4897 \\ \Delta & \mathrm{H} & \mathrm{H} & \mathrm{H} & \mathrm{H} & \mathrm{CH}_{3} & 810.4787\end{array}$

$\mathrm{H} \quad \mathrm{CO}_{2} \mathrm{H}$

$\begin{array}{lll}\mathrm{CH}_{3} & 888.4740\end{array}$

$\Delta \quad \mathrm{H}$

$\mathrm{H} \quad \mathrm{H} \quad \mathrm{H}=$

$=\mathrm{O} \quad \mathrm{CH}_{3}$

\begin{tabular}{ll}
$\mathrm{CH}_{3}$ & 810.4787 \\
$\mathrm{CH}_{3}$ & 824.4580 \\
\hline
\end{tabular}

\begin{tabular}{l|l|l|l|l|l|l}
$\Delta$ & $\mathrm{H}$ & $\mathrm{CH}_{3}$ & $\mathrm{H}$ & $\mathrm{H}$ & $\mathrm{CH}_{3}$ & 824.4943
\end{tabular}

$\Delta$

$\mathrm{H} \quad \mathrm{CH}_{3}$

$\mathrm{H}=\mathrm{O}$

$=\mathrm{O} \quad \mathrm{CH}_{3}$

\begin{tabular}{ll}
$\mathrm{CH}_{3}$ & 838.4736 \\
\hline
\end{tabular}

$\begin{array}{lllllll}\Delta & - & - & \mathrm{CH}_{3} & \mathrm{H} & \mathrm{CH}_{3} & 716.4732\end{array}$

$\begin{array}{llll}\mathrm{CH}_{3} & \mathrm{H} & \mathrm{CH}_{3} & 816.4893\end{array}$

\begin{tabular}{cc|c|c|c|c|c}
$\Delta$ & $\mathrm{OH}$ & $\mathrm{CH}_{3}$ & $\mathrm{CH}_{3}$ & $\mathrm{H}$ & $\mathrm{H}$ & 858.4998
\end{tabular}

\begin{tabular}{lll|l|l|l|l}
$\mathrm{OH}$ & $\mathrm{H}$ & $\mathrm{CH}_{3}$ & $\mathrm{H}$ & $\mathrm{H}$ & 846.4998 \\
\hline
\end{tabular}

$\begin{array}{lllllll}\Delta & \mathrm{H} & \mathrm{H} & \mathrm{CO}_{2} \mathrm{H} & \mathrm{OH} & \mathrm{CH}_{3} & 888.4740\end{array}$

$\begin{array}{lllllll}\Delta & \mathrm{H} & \mathrm{CH}_{3} & \mathrm{CO}_{2} \mathrm{H} & \mathrm{OH} & \mathrm{CH}_{3} & 902.4897\end{array}$

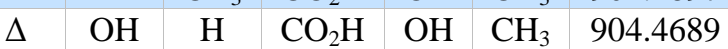

Origin*

$\mathrm{EC}_{50}$

relative

potency

1.0

Abiotic

5.1

Algal

8.3

shellfish/abiotic

4.5

shellfish/abiotic $\quad 0.6$

shellfish/abiotic $\quad 0.4$

shellfish/abiotic $\quad 7.0$

shellfish

shellfish

4.5

shellfish/abiotic $\quad 0.4$

shellfish/abiotic $\quad 0.2$

shellfish

shellfish

shellfish/abiotic

shellfish

shellfish/abiotic

shellfish

shellfish

shellfish

shellfish

shellfish

shellfish/abiotic

shellfish/abiotic

0.03

shellfish/abiotic

shellfish/abiotic

\begin{tabular}{|c|c|}
\hline Algal & 0.2 \\
Algal & 5.5 \\
Algal & 0.2 \\
\hline Algal & 0.3 \\
\hline shellfish & \\
shellfish & \\
\hline shellfish & \\
\hline shellfish & \\
\hline
\end{tabular}




\begin{tabular}{|l|l|l|l|c|c|c|c|c|c|}
\hline AZA48 (4) & a2 & $\Delta$ & $\mathrm{OH}$ & $\mathrm{H}$ & $\mathrm{H}$ & $\mathrm{H}$ & $\mathrm{CH}_{3}$ & 826.4736 & shellfish/abiotic \\
\hline AZA49 & $\mathrm{a} 2$ & $\Delta$ & $\mathrm{OH}$ & $\mathrm{CH}_{3}$ & $\mathrm{H}$ & $\mathrm{H}$ & $\mathrm{CH}_{3}$ & 840.4893 & shellfish/abiotic \\
\hline AZA60 & $\mathrm{a} 2$ & $\Delta$ & $\mathrm{H}$ & $\mathrm{H}$ & $\mathrm{H}$ & $\mathrm{OH}$ & $\mathrm{CH}_{3}$ & 826.4736 & shellfish/abiotic \\
\hline AZA61 & $\mathrm{a} 2$ & $\Delta$ & $\mathrm{H}$ & $\mathrm{CH}_{3}$ & $\mathrm{H}$ & $\mathrm{OH}$ & $\mathrm{CH}_{3}$ & 840.4893 & shellfish/abiotic \\
\hline
\end{tabular}

Compounds highlighted in grey have had their structures confirmed by NMR; compounds highlighted in blue have had their structures confirmed by decarboxylation to known compounds; compounds highlighted in yellow have had their structures confirmed following heat/acid-catalysed formation from known compounds; \# orientation of the methyl group at C37. The type refers to variations of the LHS and RHS parts of the molecule. *AZAs are considered to originate from algae, from metabolism of algal AZAs in shellfish, or from natural apparently abiotic processes such as 22-decarboxylation, 21,22-dehydration or 37-epimerization.

Figure 1. Structures and protonated masses, origin and $\mathrm{EC}_{50}$ (relative to AZA1) of AZAs. 


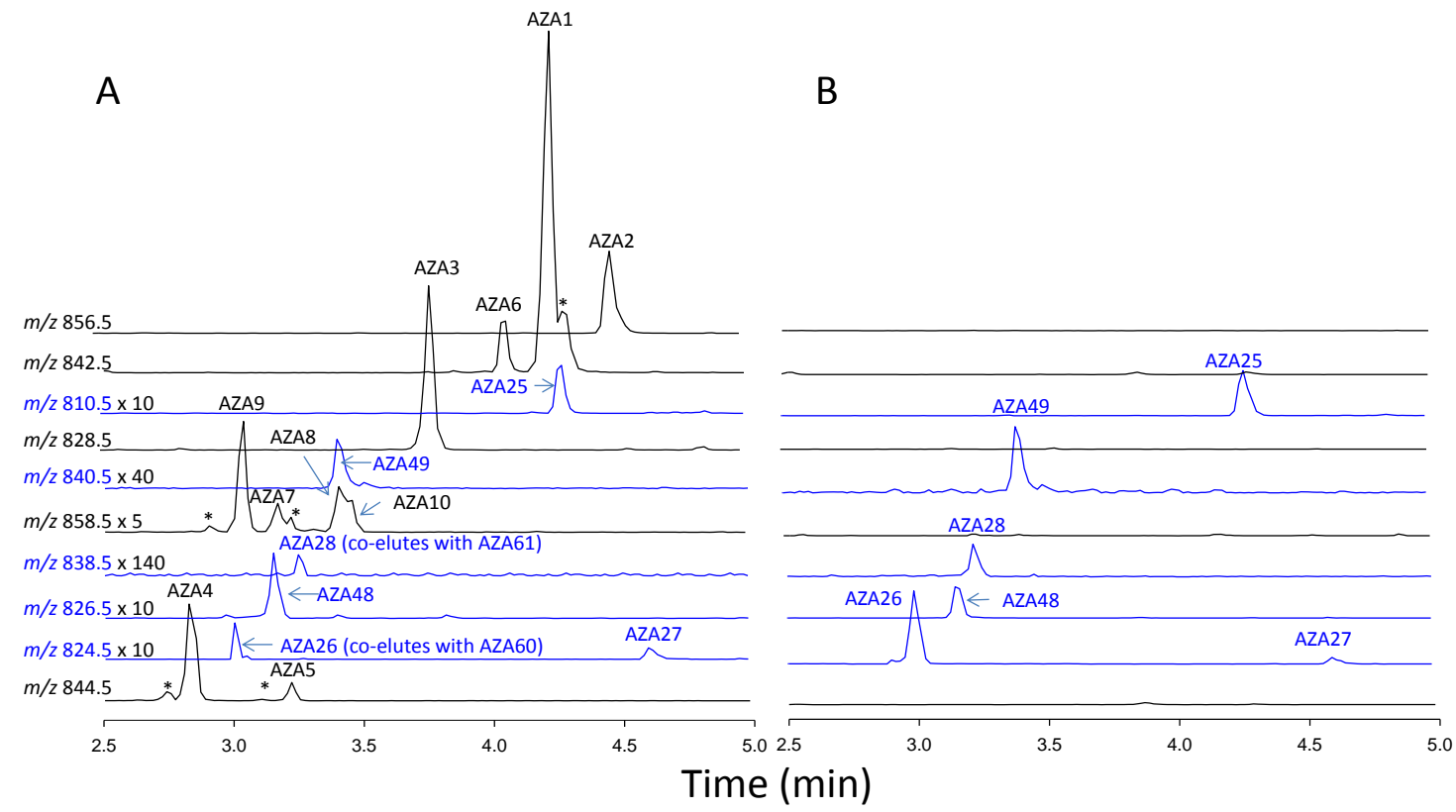

Figure 2. Chromatographic separation of: A) AZA1-10 and the 21,22-dehydro analogues (blue) for AZA3 (AZA25), AZA4 (AZA48), AZA5 (AZA60), AZA6 (AZA27), AZA9 (AZA49) and AZA10 (AZA61) and C-23 oxidised AZA60 (AZA26) and AZA61 (AZA28) in a cooked hepatopancreas extract, and; B) after treatment with periodate using method A (i). * indicates the presence of the 37 -epimers. ${ }^{17}$

Note. Using method A (i), AZA60 co-elutes with AZA26 and AZA61 co-elutes with AZA28, but separation could be achieved using method A (ii) (Figures S5 and S6). 


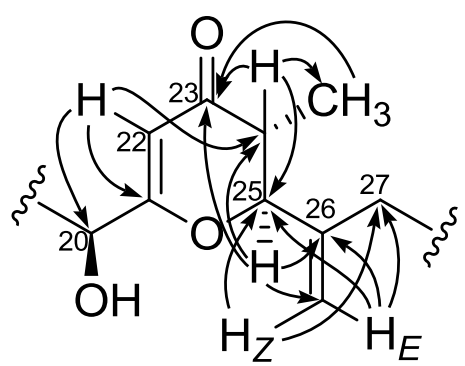

Figure 3. Structurally significant HMBC NMR correlations observed around the E-ring of AZA26 (3). 

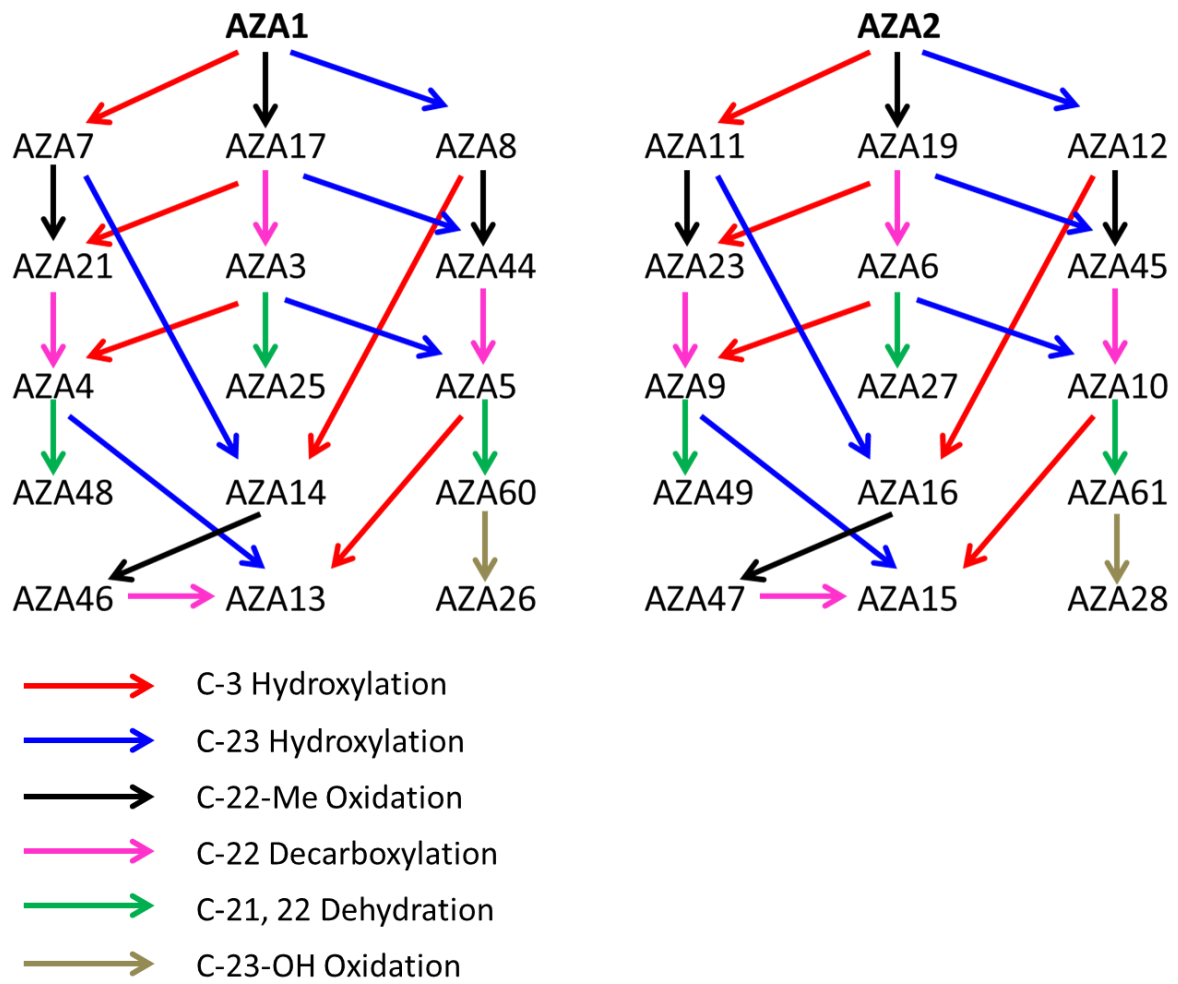

Figure 4. Proposed formation pathway for AZA25, -26, -27, -28, -48, -49, -60 and -61 (see also Figure S47). 
TOC

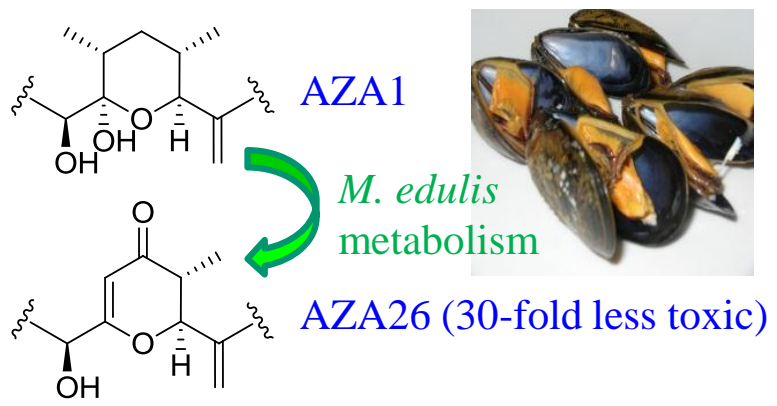

